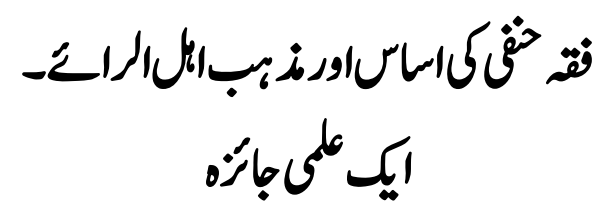

The basic of Fiqh Hanfi and the religions of Rationalists in Fiqh

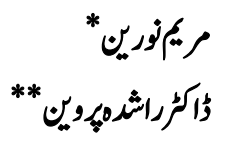

\begin{abstract}
The opponents of the Great Imam Abu Haneefa are of the view that he, while resolving any new mas'ala or issue, prefers logical considerations as compared to Quran and Hadith. On this a great amount of proofs have been produced by the Hanfi scholars that it is not the case. Imam Abu Haneefa never attempted to violate any rule of "Usoolal.Fiqh" while deducing any new verdict. He has clearly said that when a clear cut and thoroughly proved correct Hadith is found by him, he decides by that, but when there is no such thing available he uses his common sense to solve the problem for the relief of the people. He asserts that Religion, "Deen" is to facilitate the public and not to put them in trouble.

In this reference, he has clarified the situation by saying that "when I find Quranic proof I pick that, but when I don't find that I choose (to study) the Hadith of the Prophet (PBUH), the traditions of His followers which are fully authentic. When I do not find the same (issue) in Quran and Hadith as well, I adopt the sayings of the companions of the Prophet (PBUH). However, whichever of the sayings of the companions is liked by me I take the same and leave the others. I do not adopt sayings of any other one. When "AbrahimSh'abi", Hussain Abn Sireen and Saeed Bin Al-Museeb did so, it becomes also my right to do "Ijtihad". He claims that it is not deciding by Ray or like dislike but it is "Ijtihad".

Bieng a great God Fearing person no one can claim that he might have taken any decision or given verdict for other consideration. Shah Waliullah, a great "Religious scholar" of the Sub-Continent says "Fiqh Hanfi is the most righteous sect that is following the "al'Sunat-Al Sahiha".

This and so many other facts and figures have been discussed in the article before hand which is an interesting topic opening a gate way for further research in future.
\end{abstract}

Key Words: Ray, Logical considerations, Common sense, Imam Abu Haneefa.

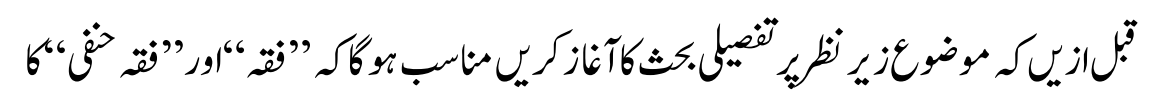

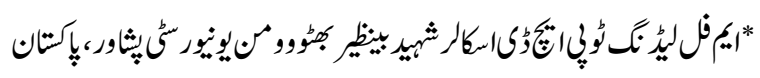

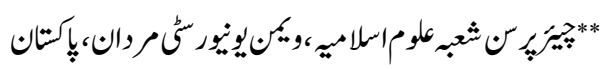




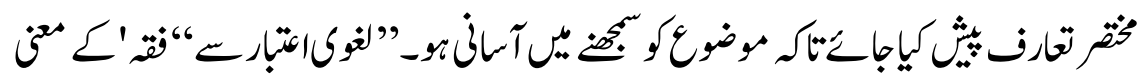

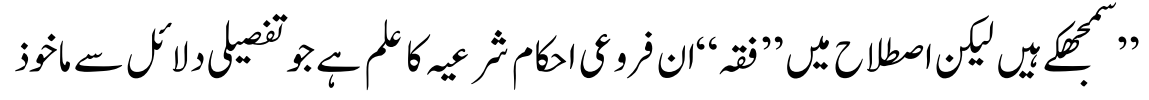

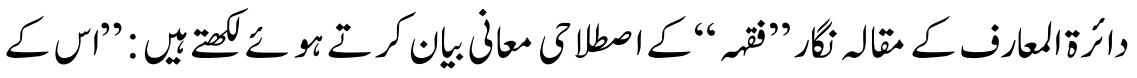

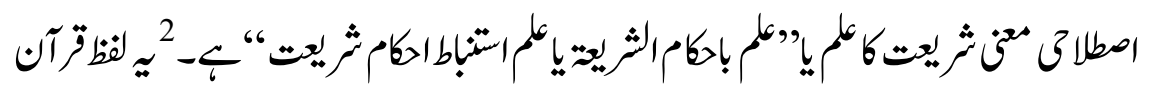

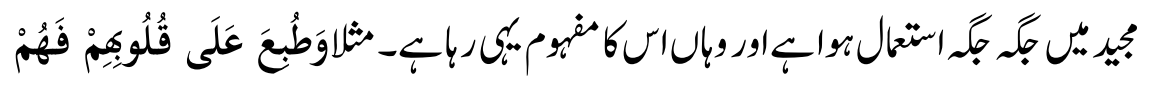

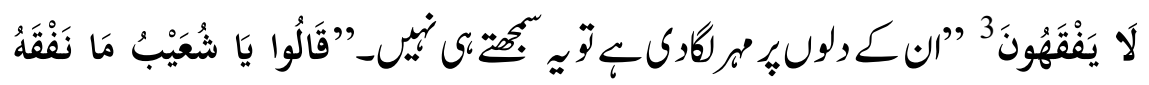

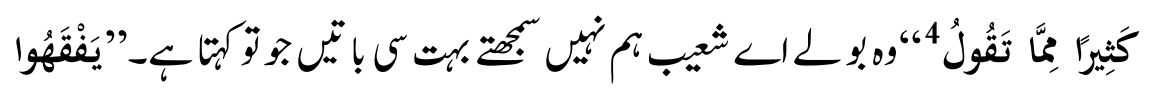

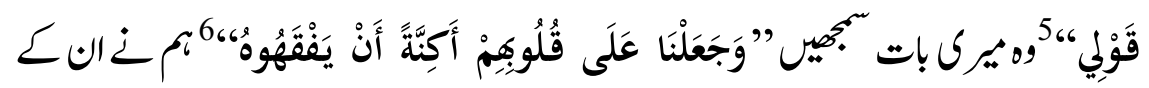

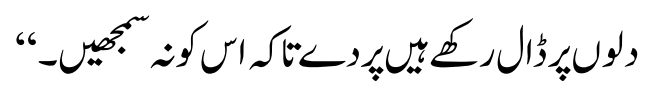

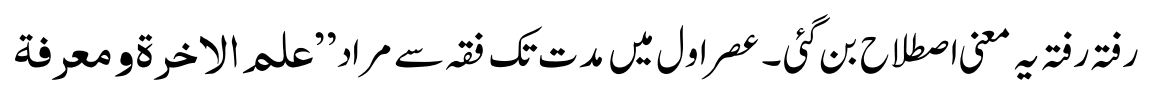

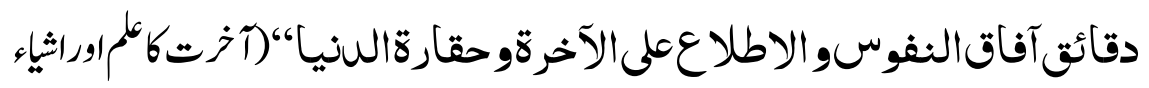

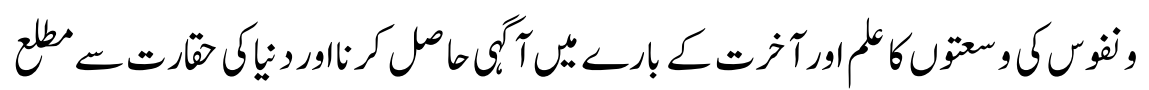

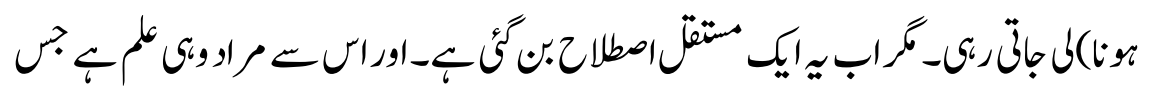

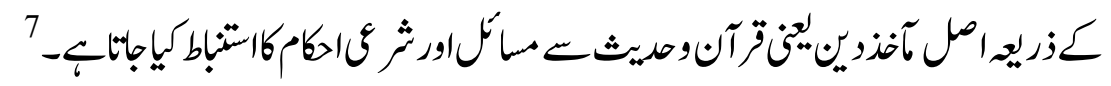

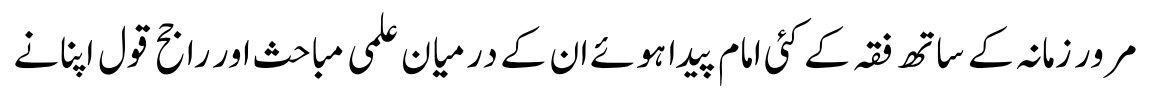

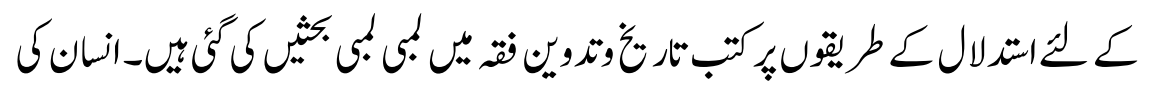

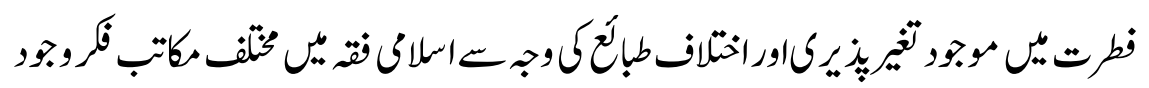

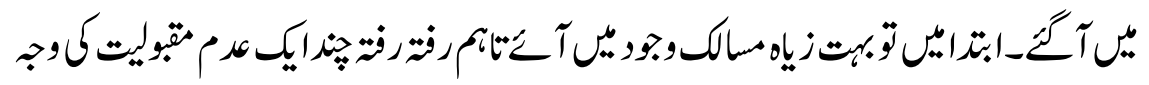

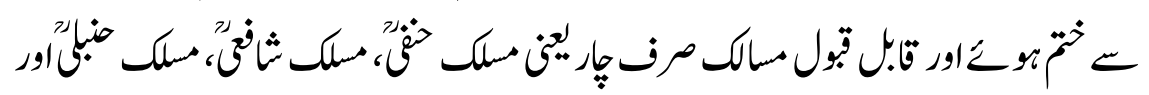




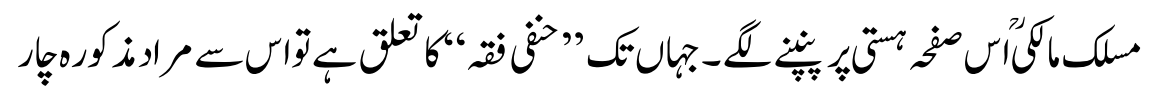

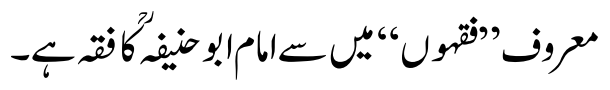

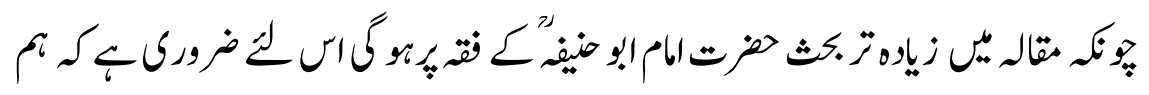

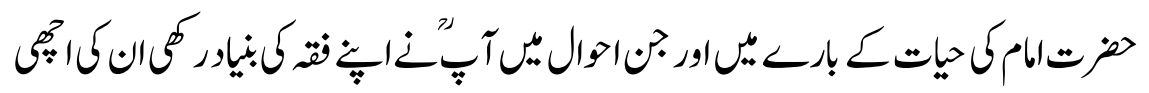

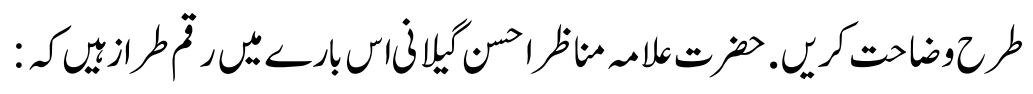

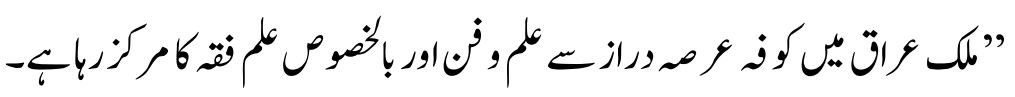

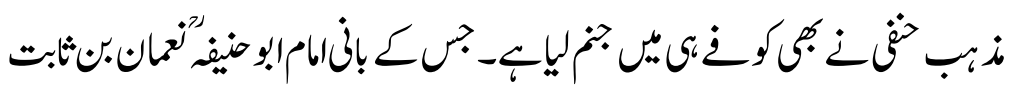

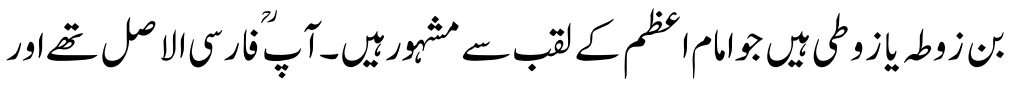

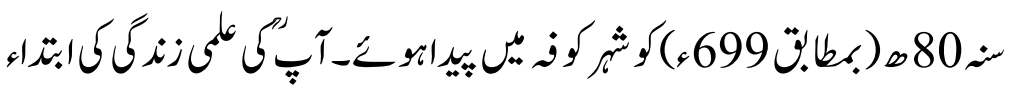

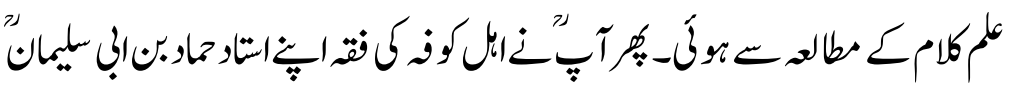

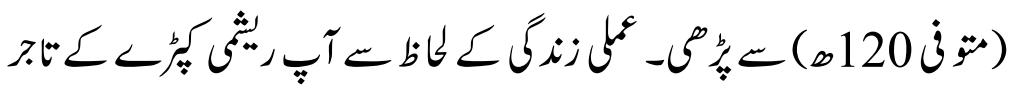

\section{$8 ،-\ddot{E}$}

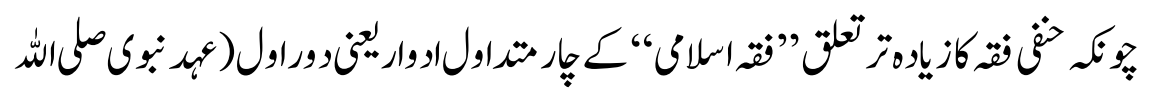

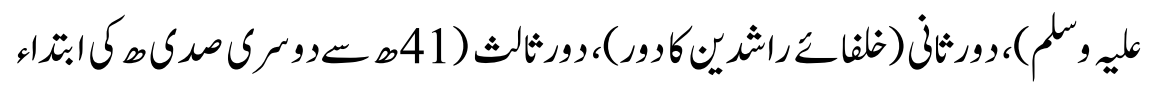

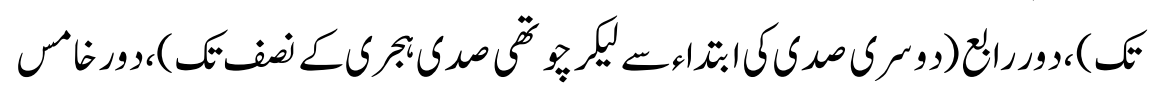

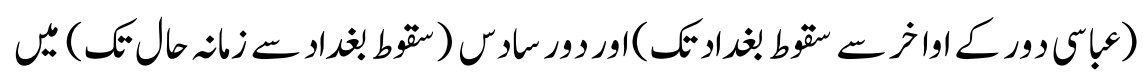

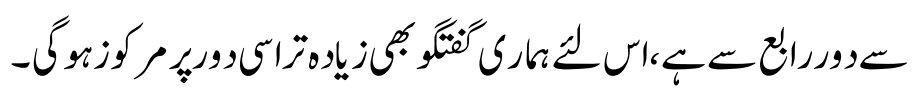

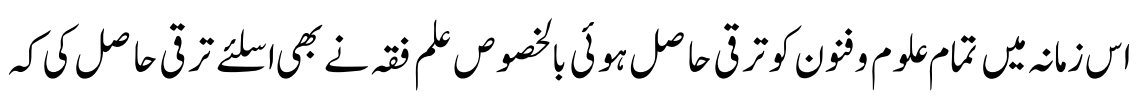

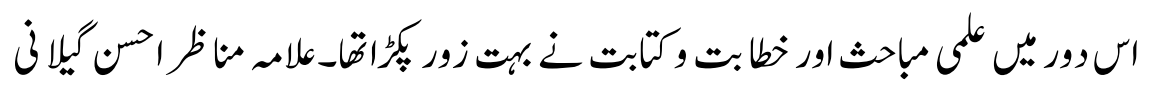
رقمرازئ 


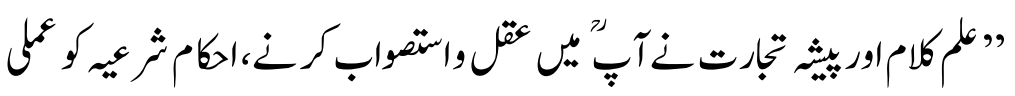

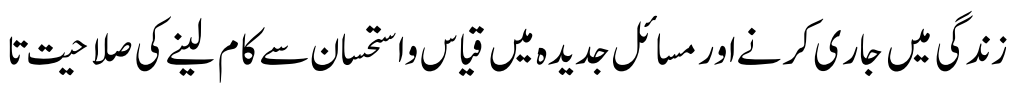

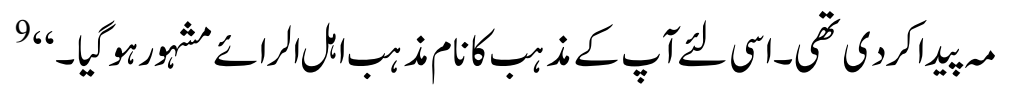

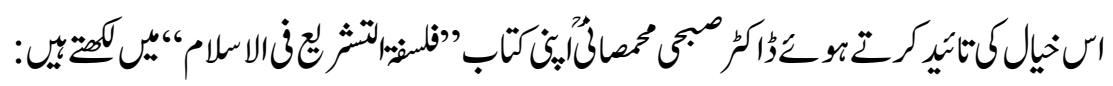

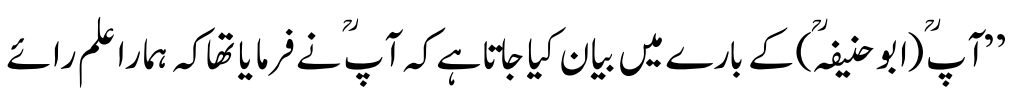

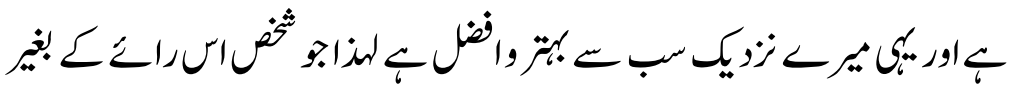

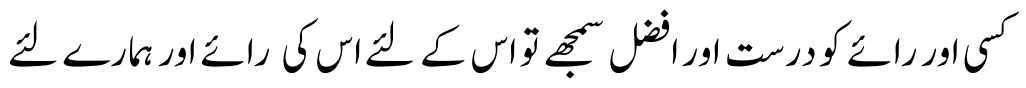

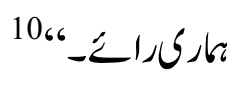

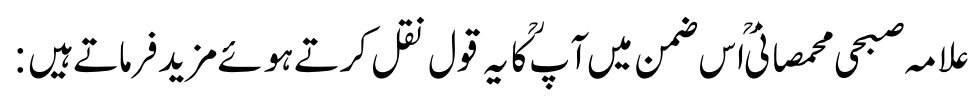

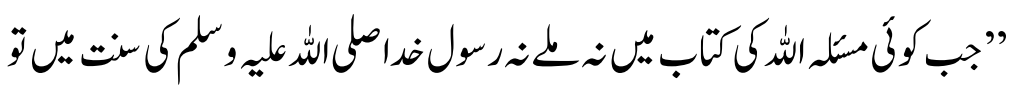

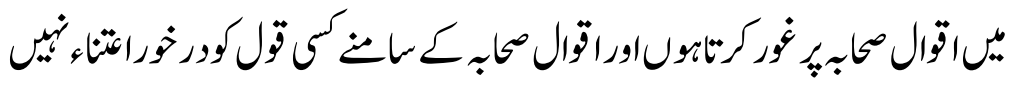

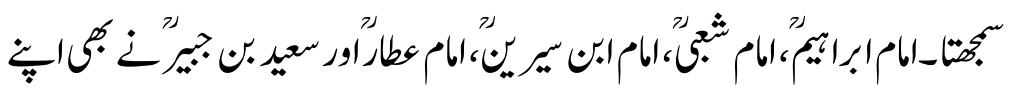

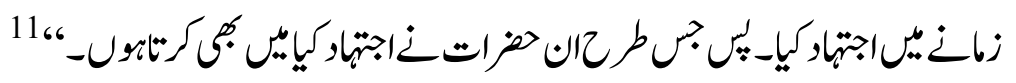

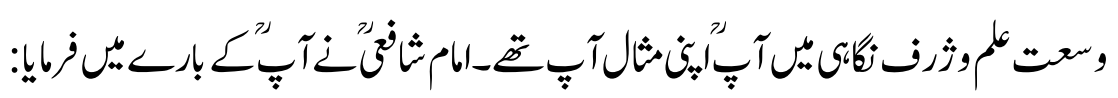

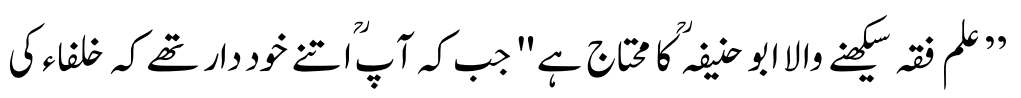

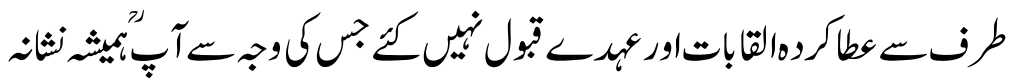

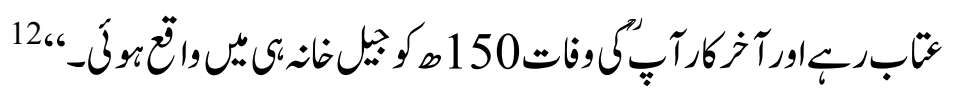

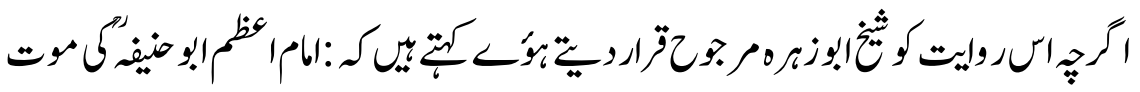

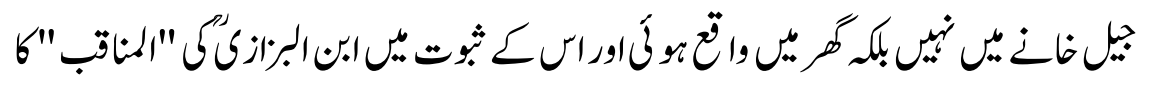

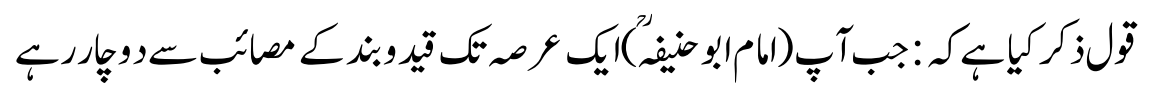

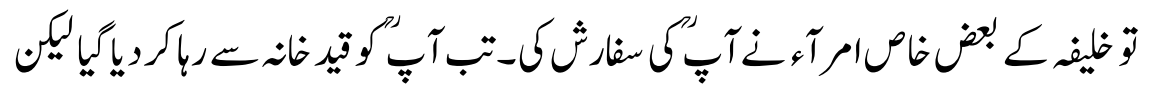




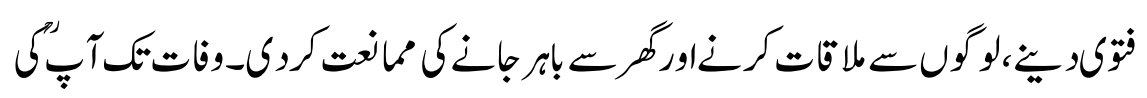

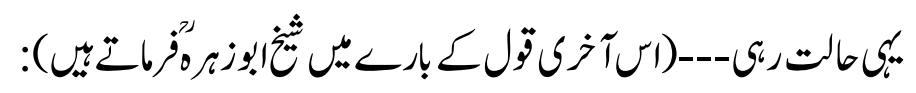

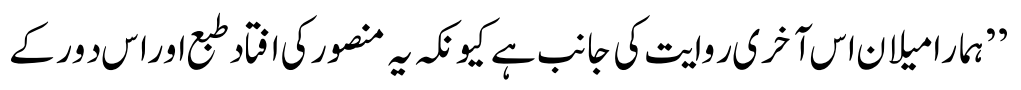

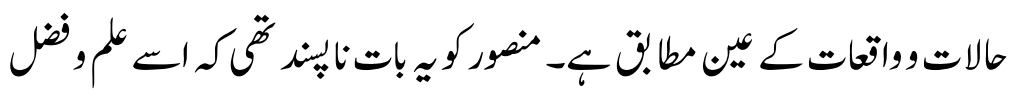

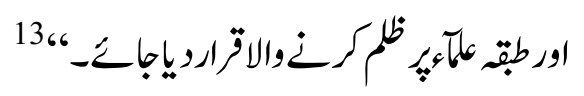

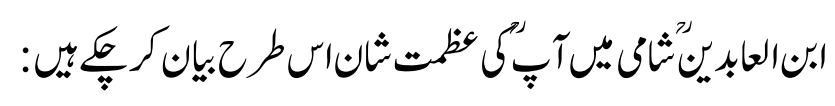

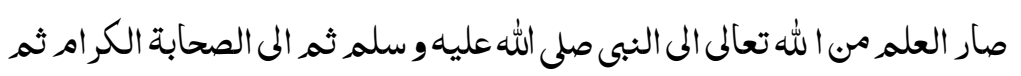

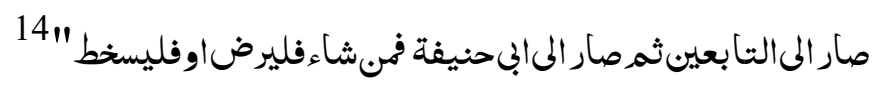

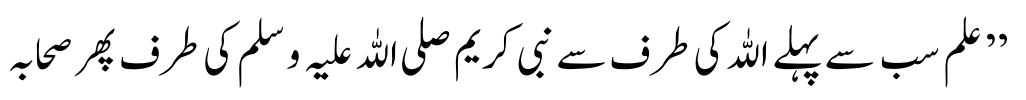

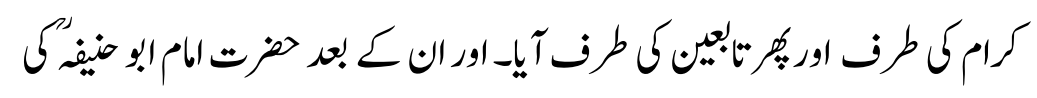

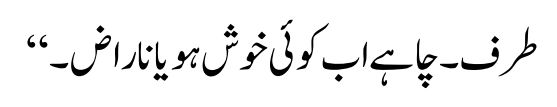

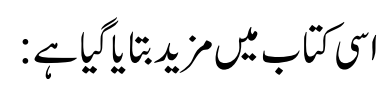

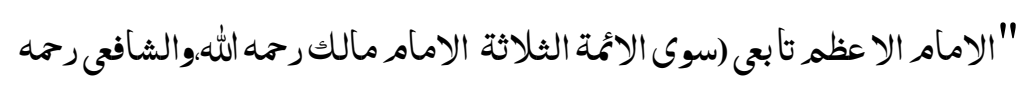

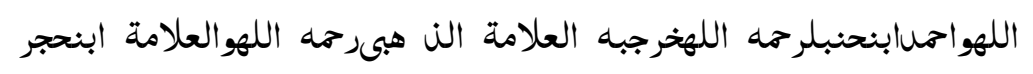

\section{العسقلانيرحها اللهوغيرهها- 15}

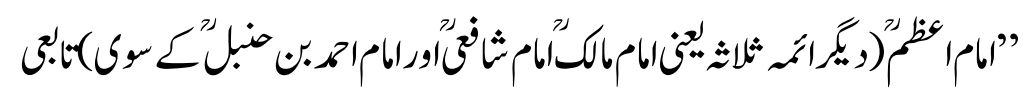

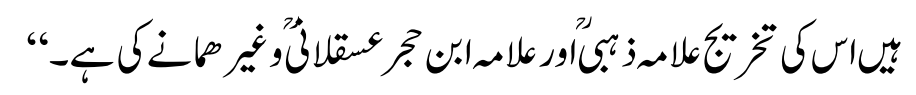

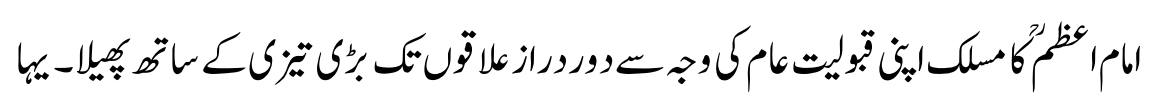

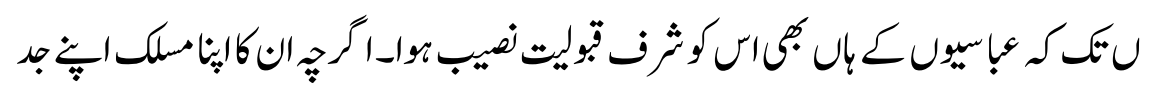

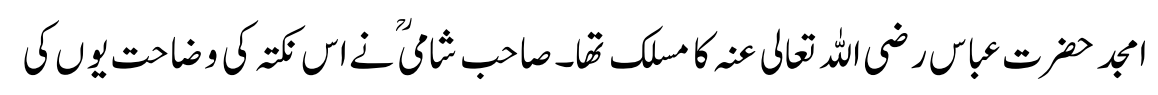




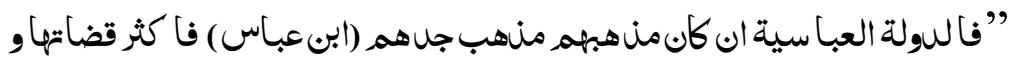

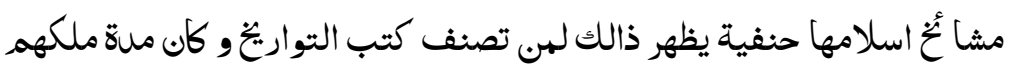

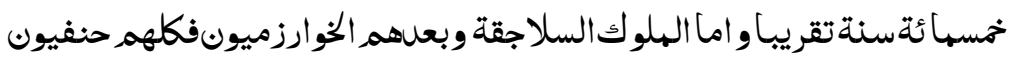

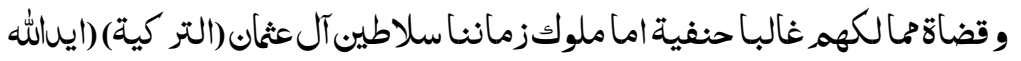

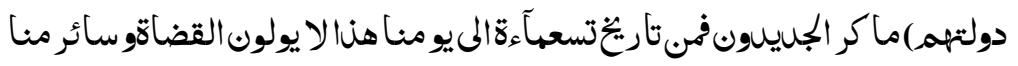
صبهم الاالحنفيةآه، ـ 16

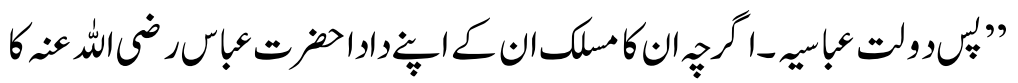

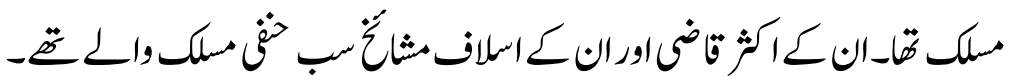

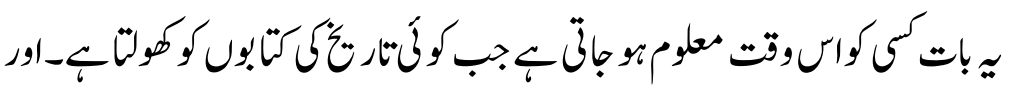

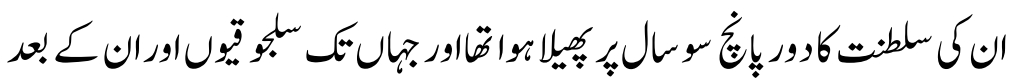

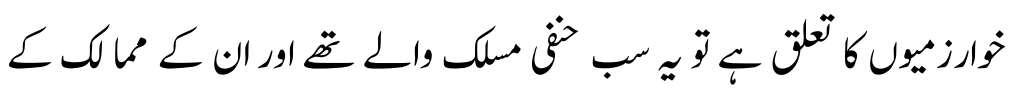

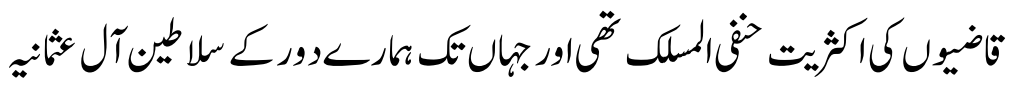

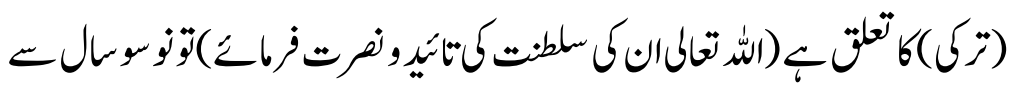

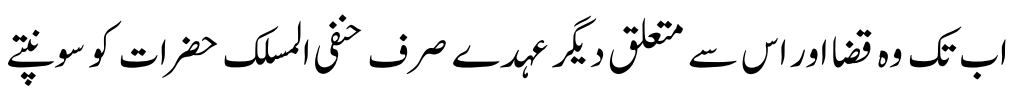
".

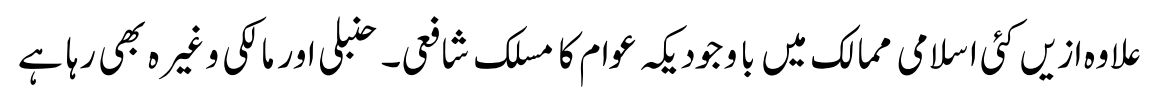

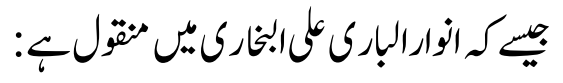

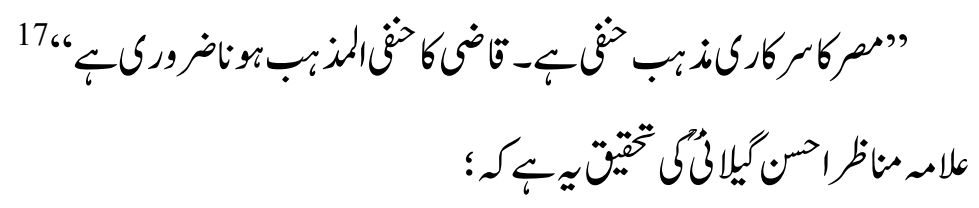

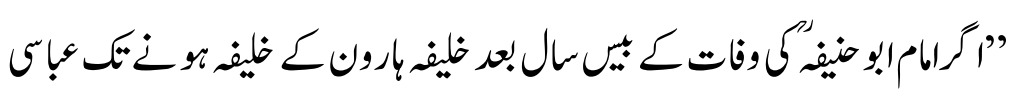

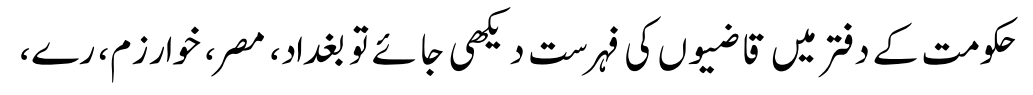




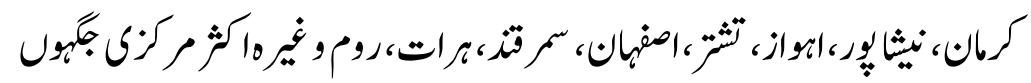

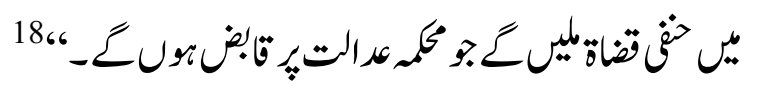

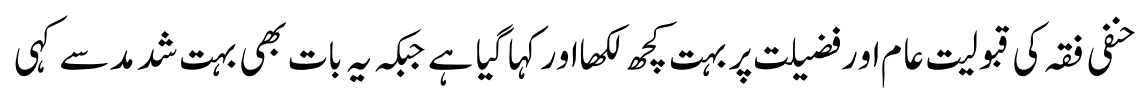

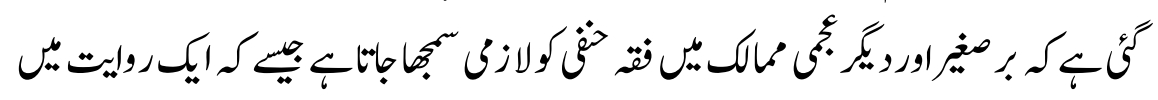
$: \sqrt{6}$

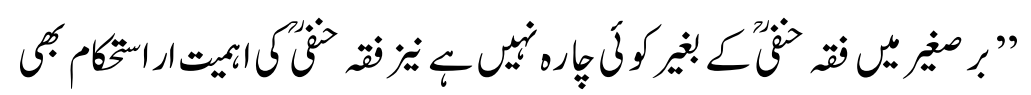

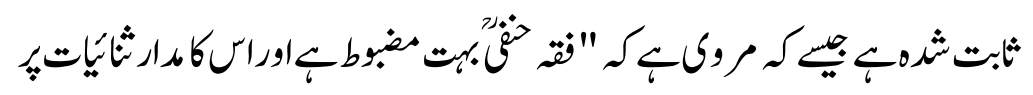

$$
196601--c
$$

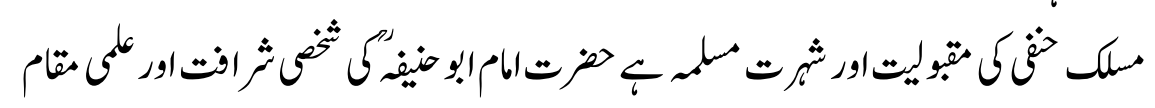

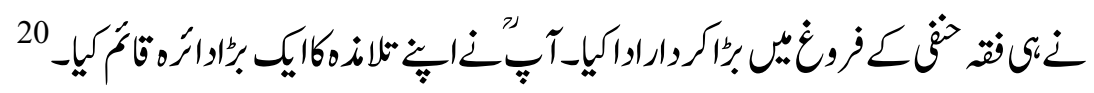

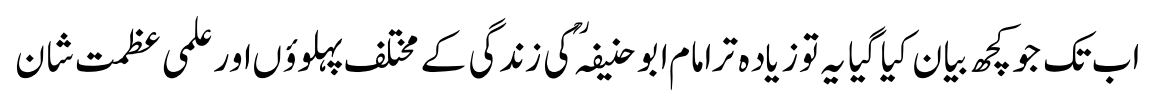

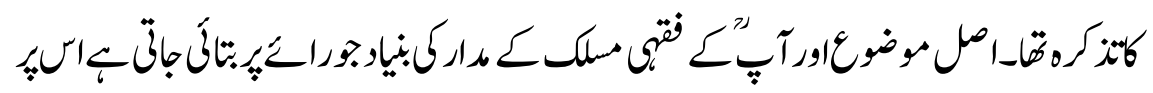

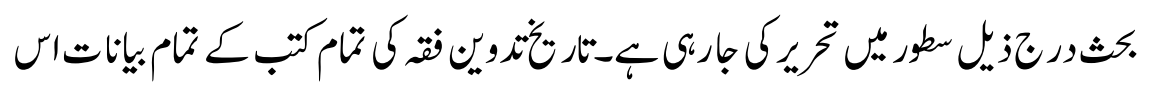

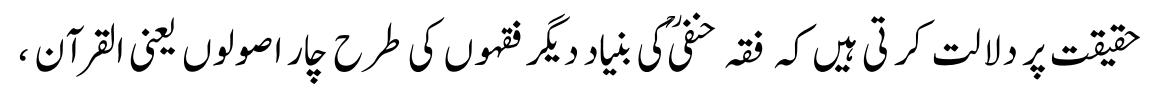

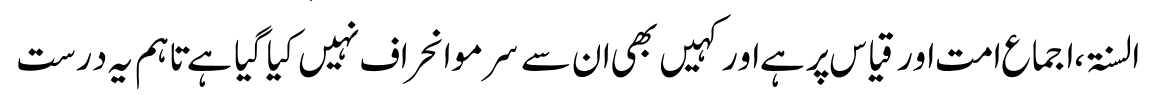

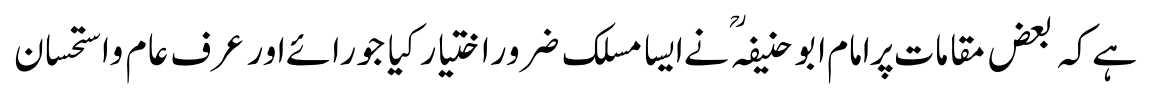

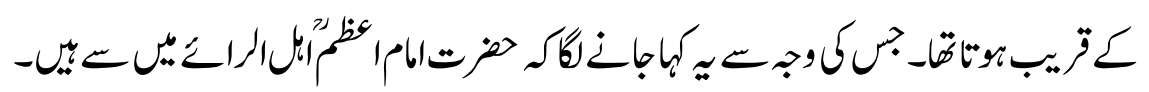

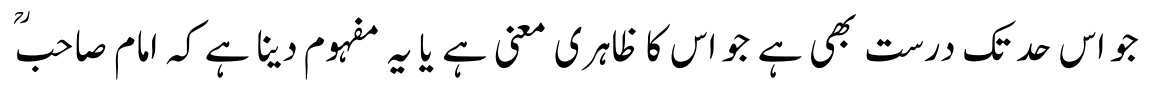

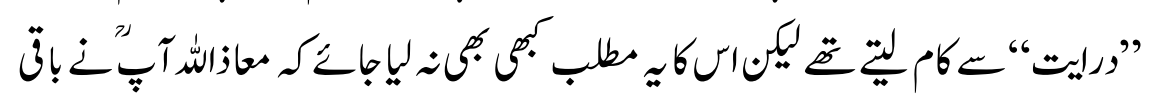

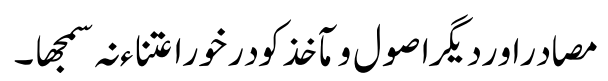

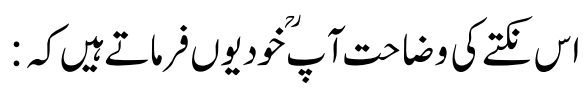




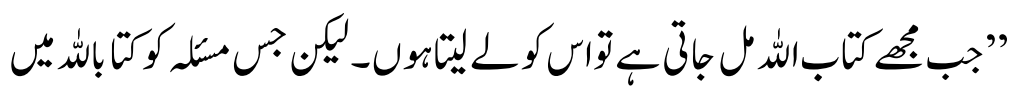

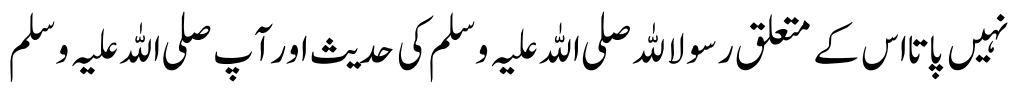

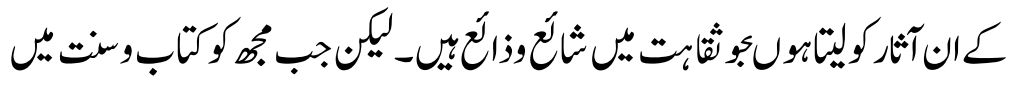

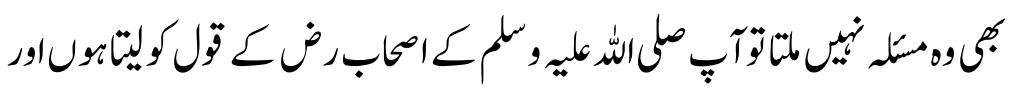

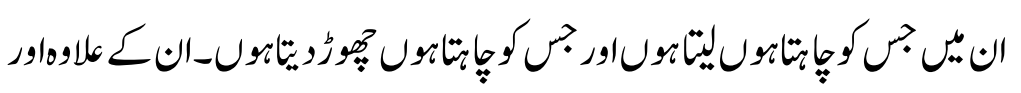

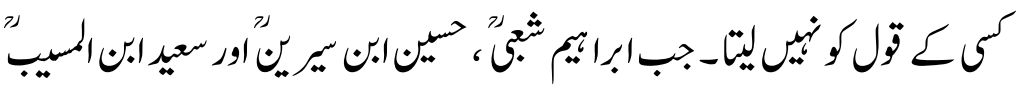

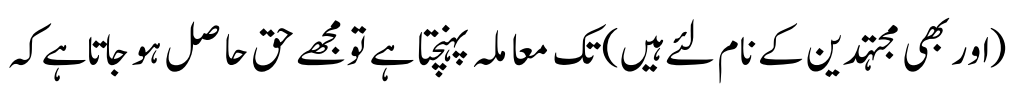

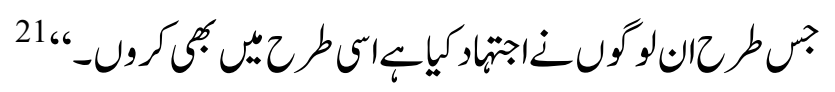

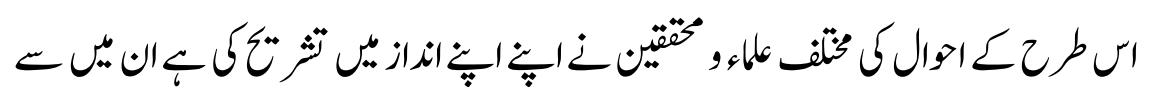

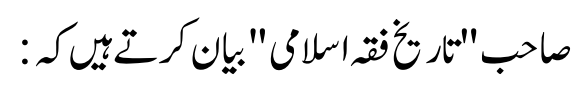

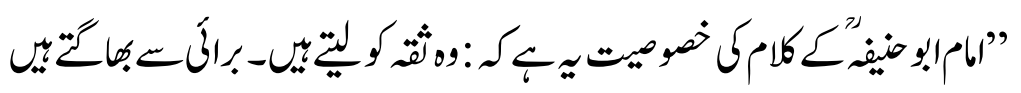

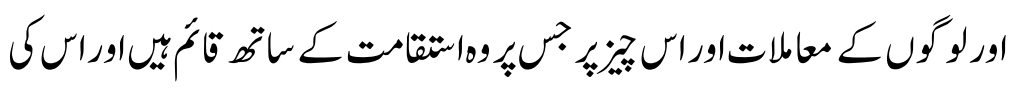

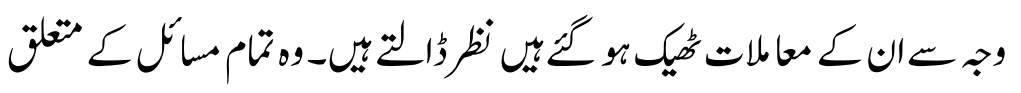

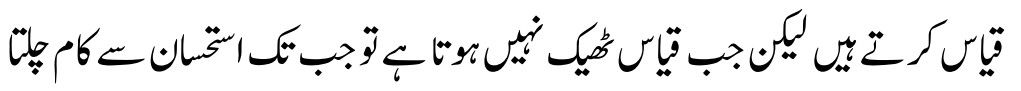

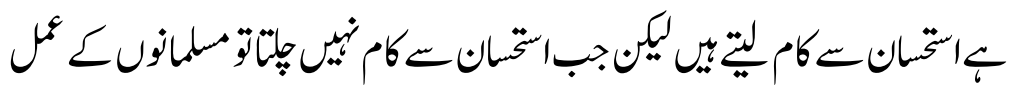

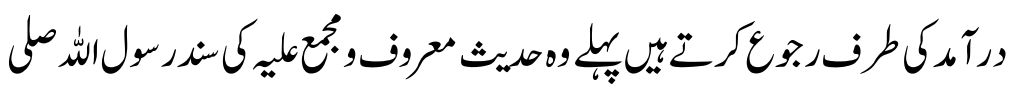

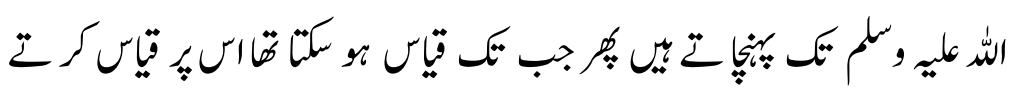

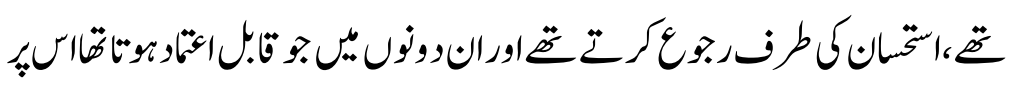

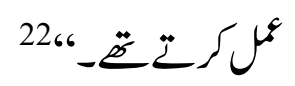




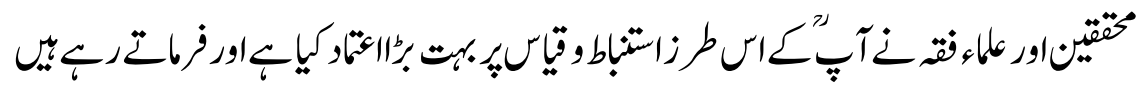

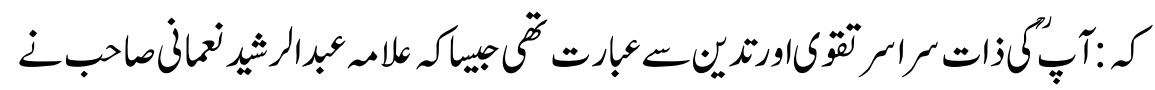

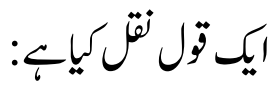

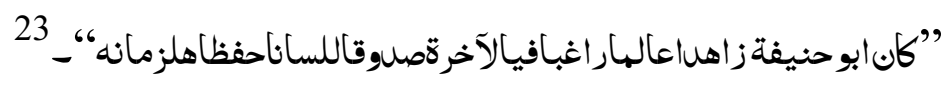

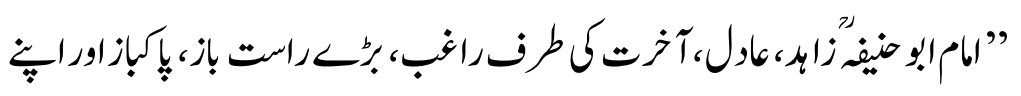

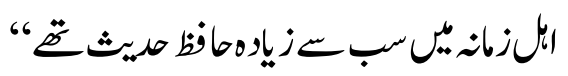

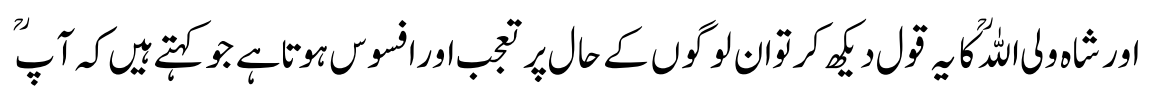

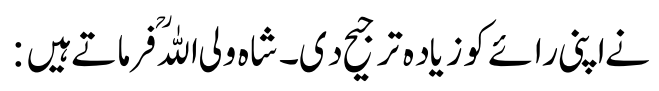

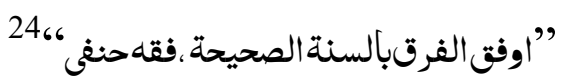

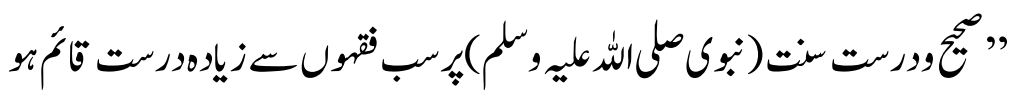

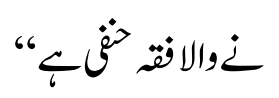

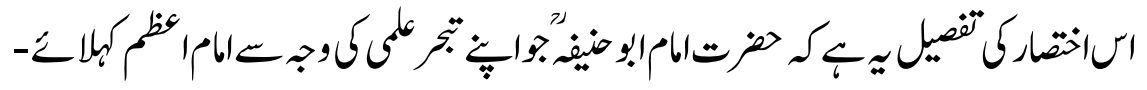

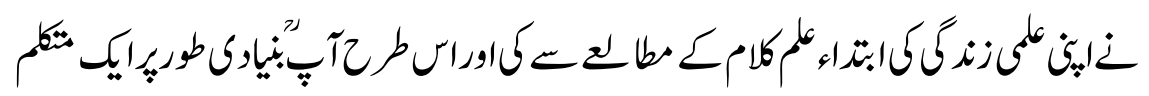

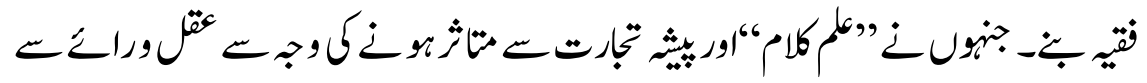

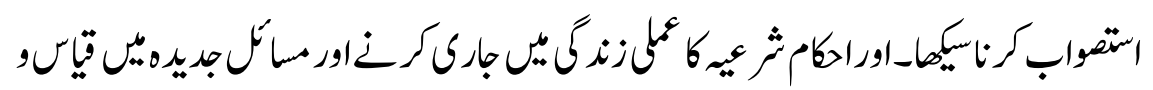

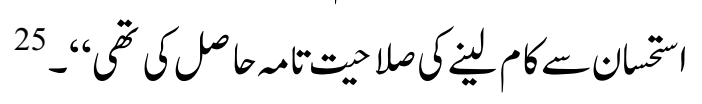

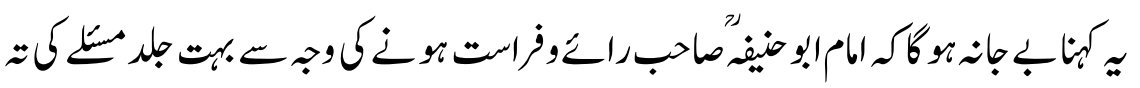

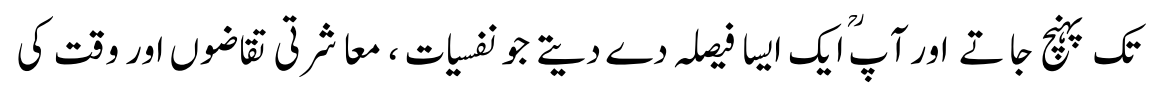

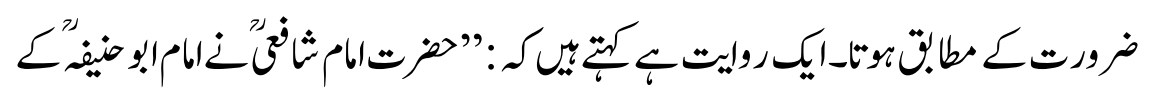

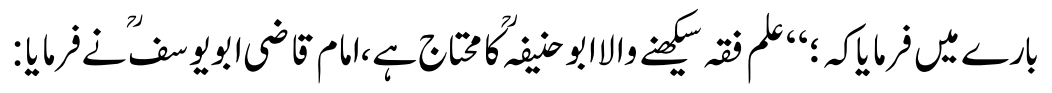




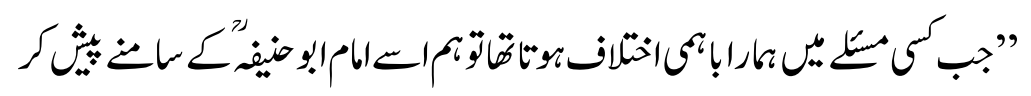

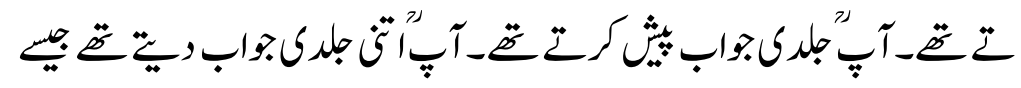

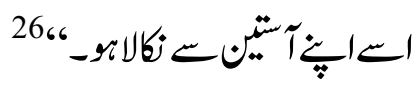

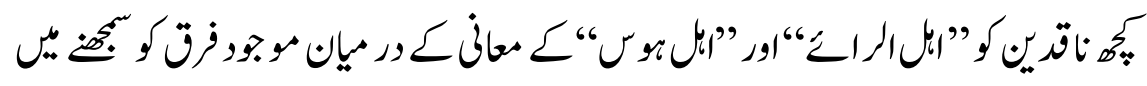

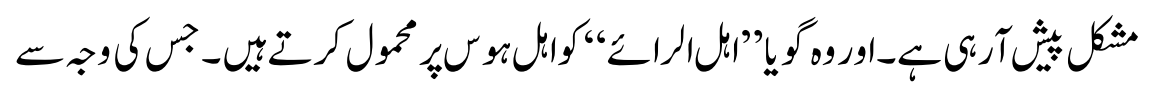

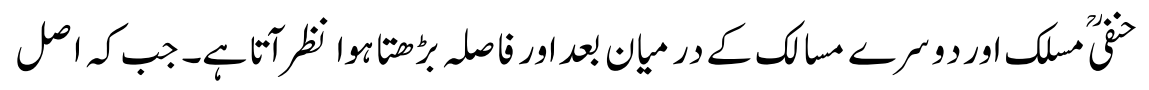

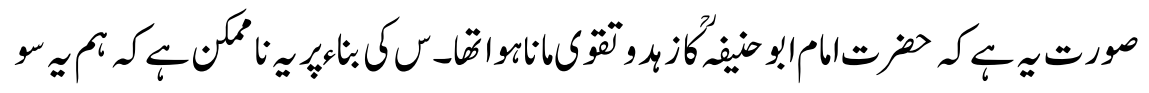

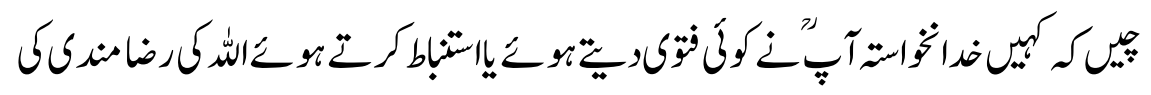

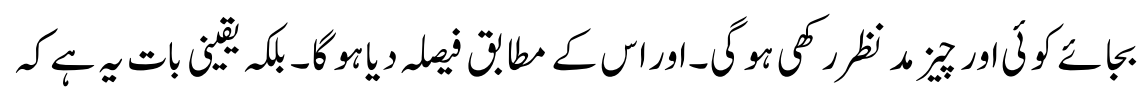

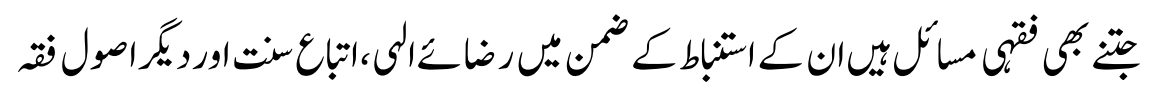

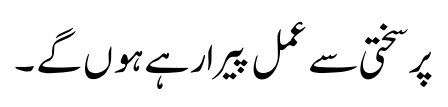

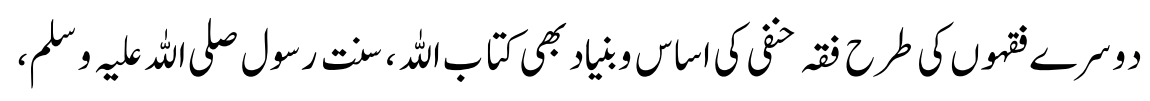

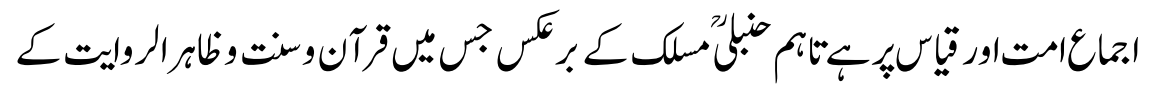

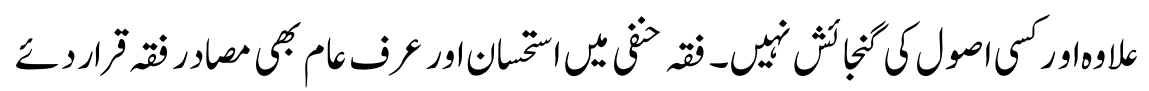

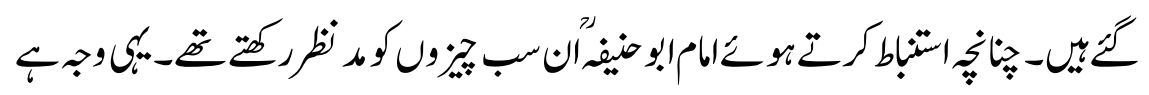

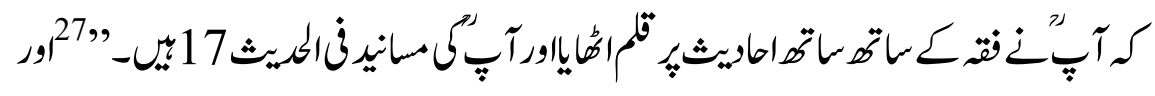

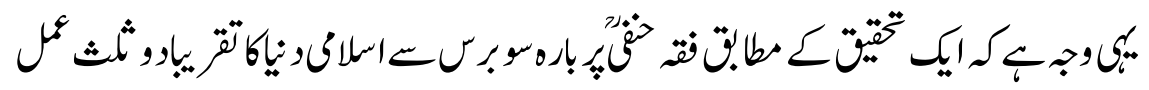

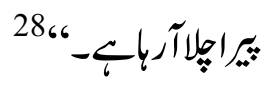

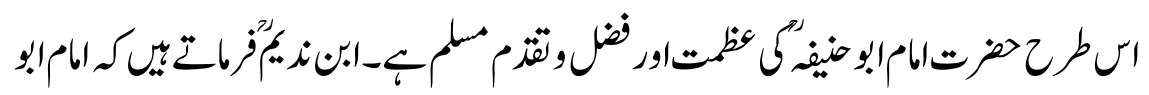

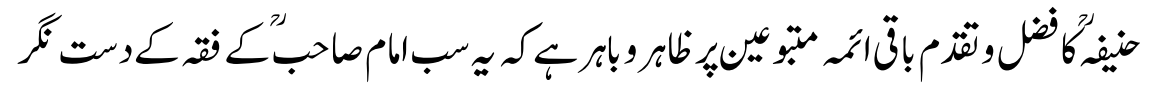




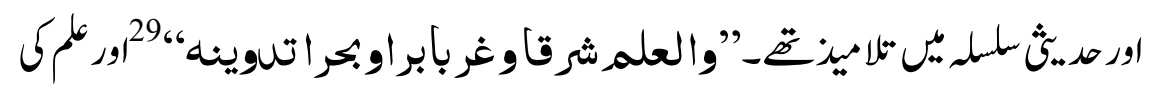

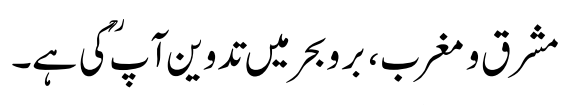

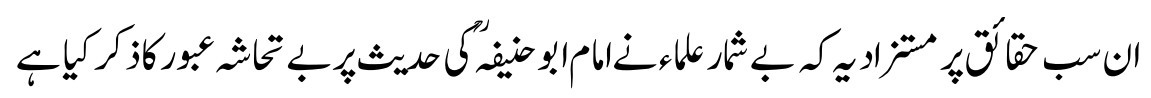

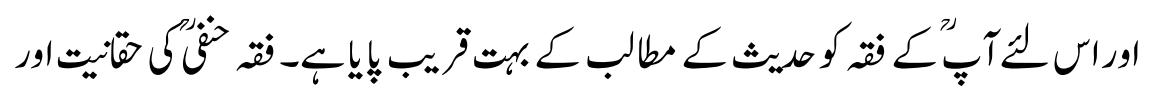

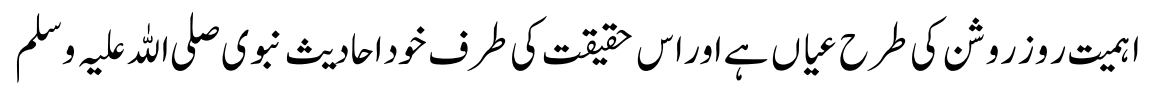

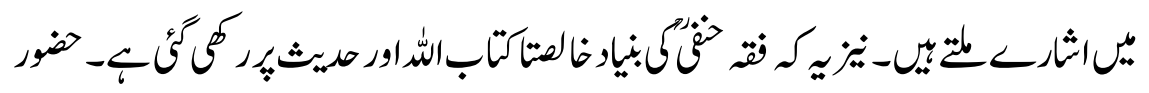

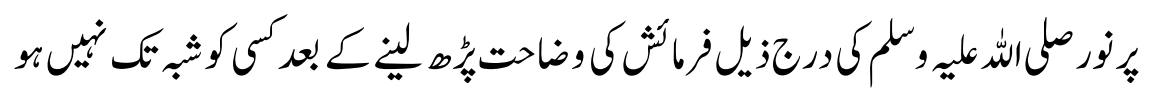

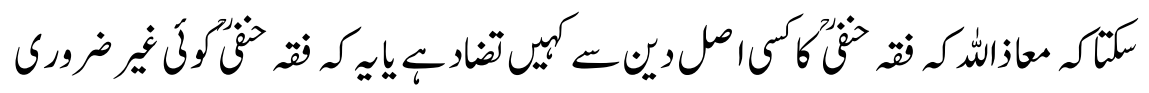

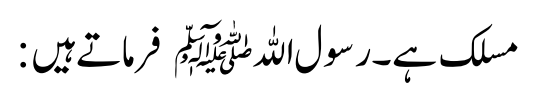

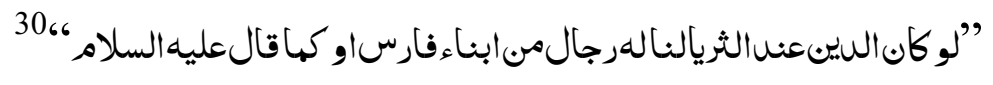

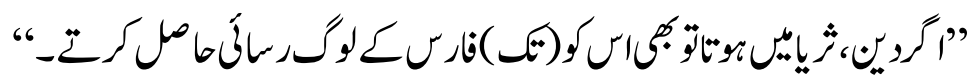

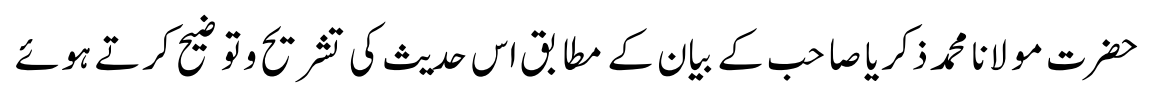

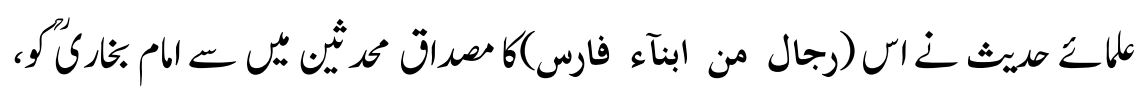

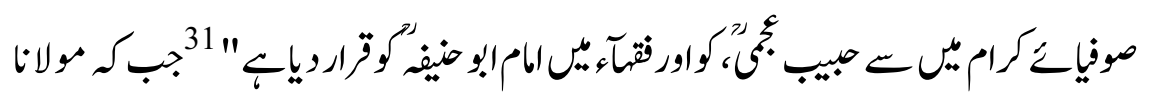

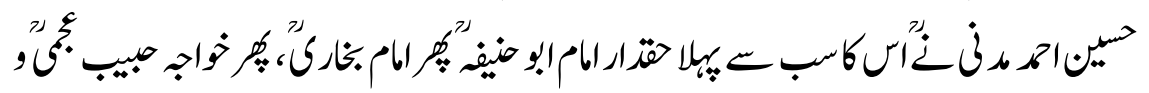

$$
\text { نيرهكوزاروياب- }
$$

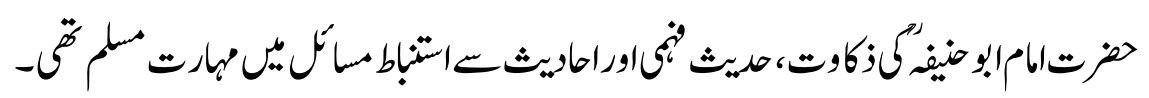

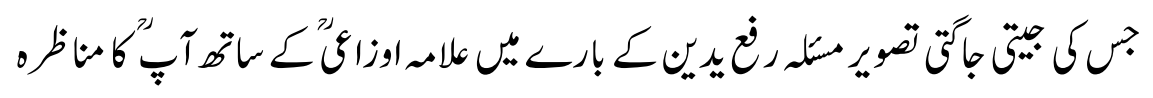

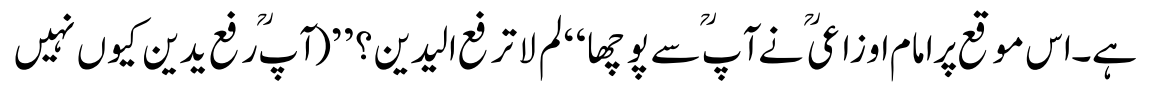

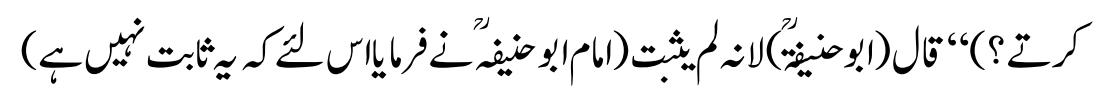


قال الا وزاعى حلثنا الزهرى عنسالمعنابنعهررضانالنبيصلياللهعليهوسلم،كانيرفح"

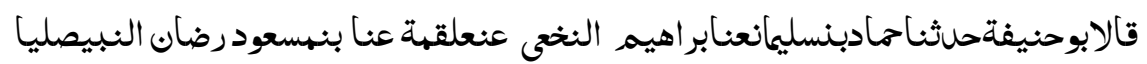

للهعلى هوسلهكانلايرفع".

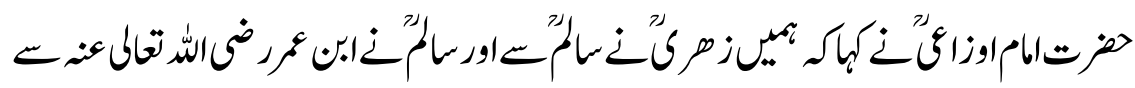

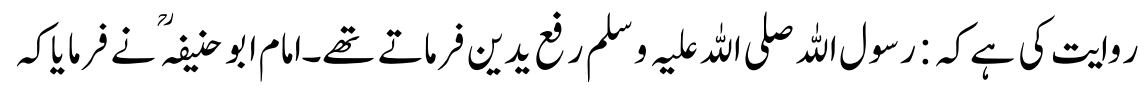

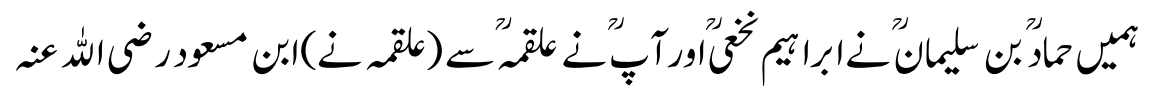

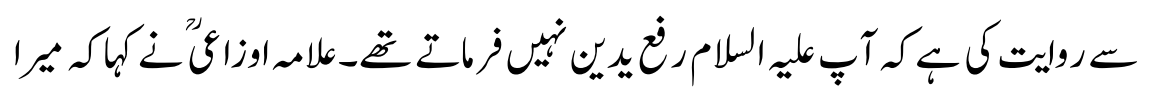

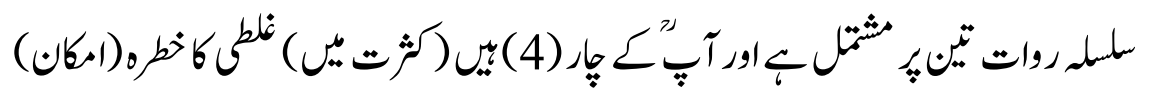

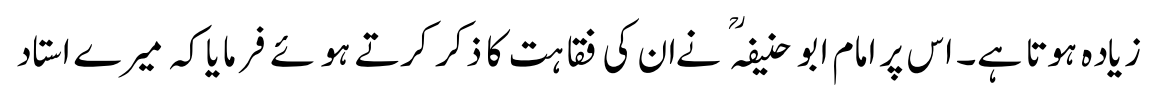

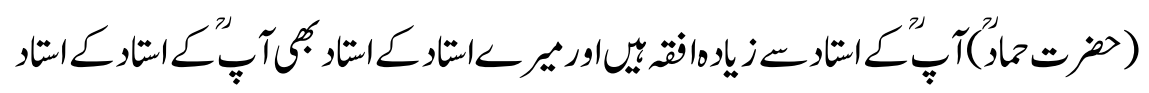

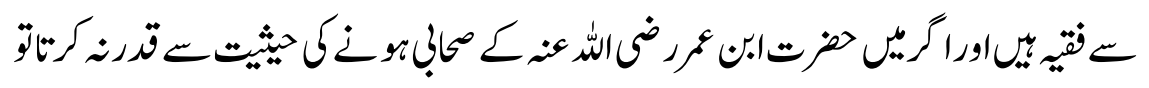

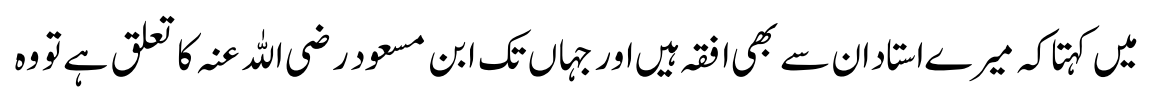

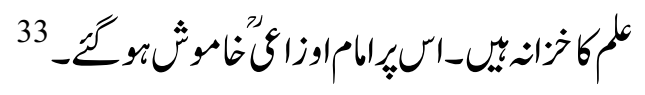

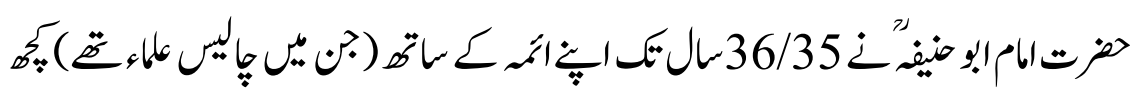

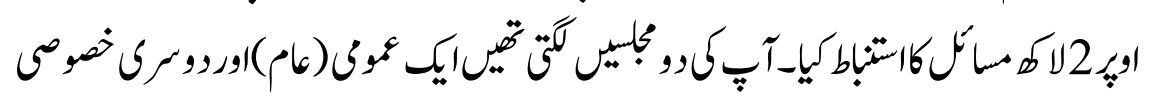

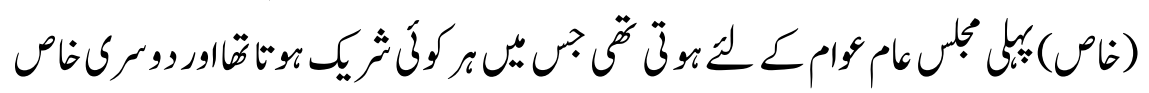

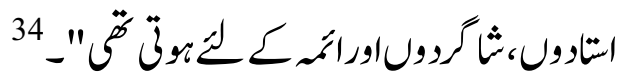

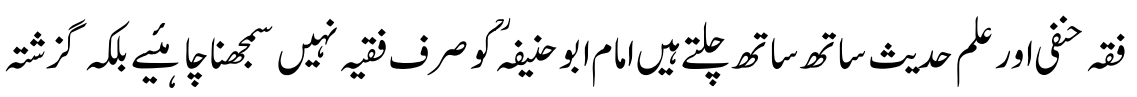

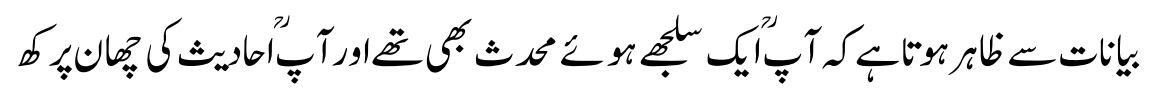

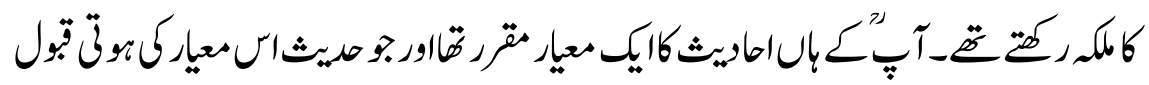

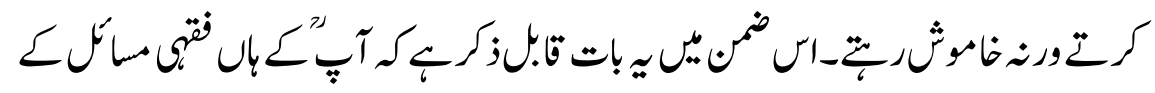




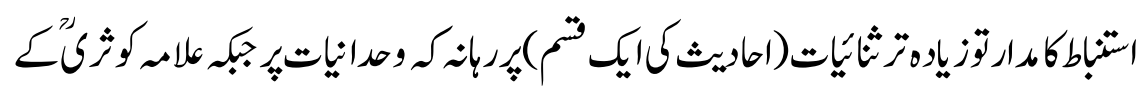

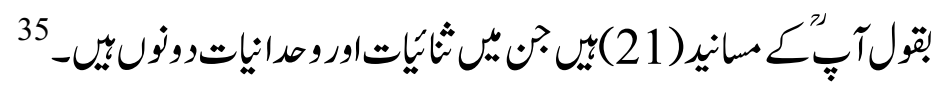

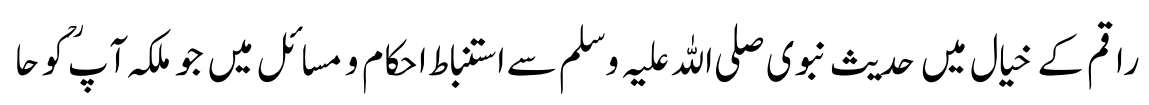

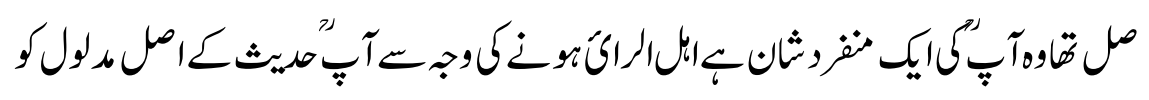

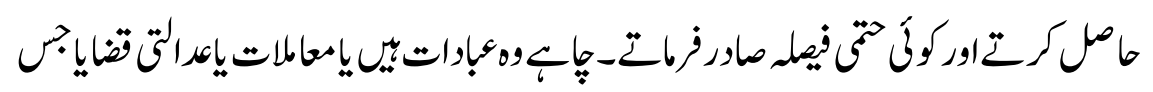

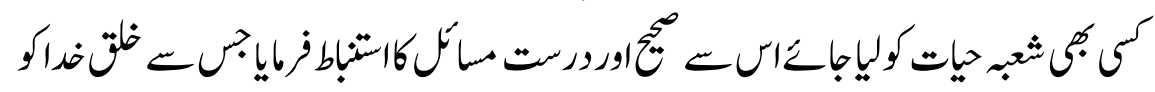

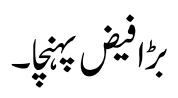

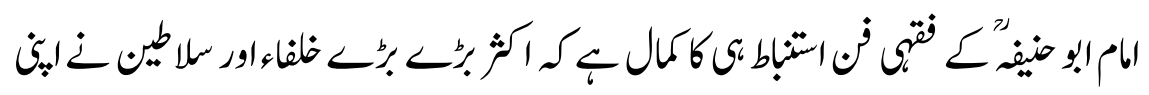

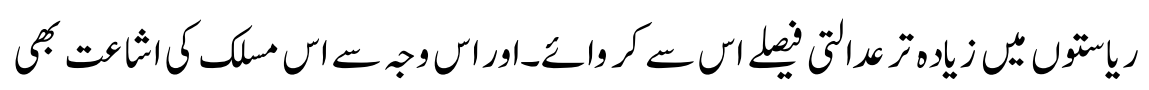

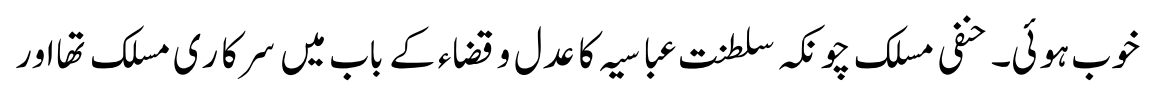

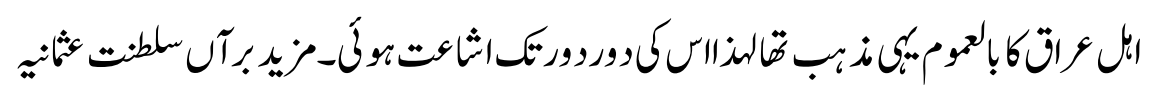

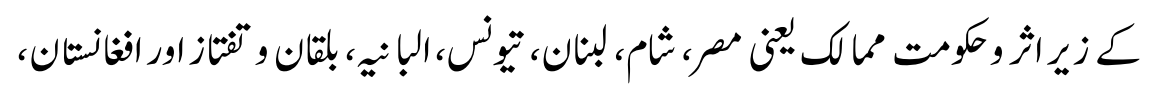

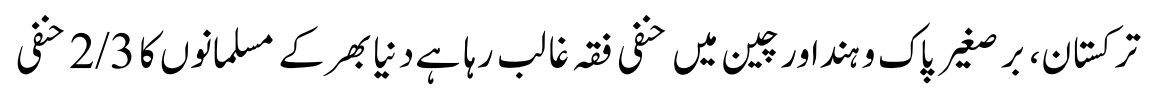

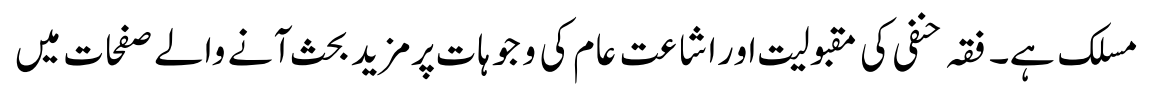
جاركاء

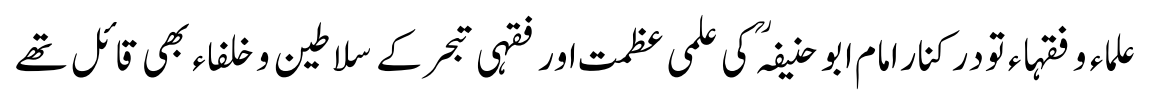

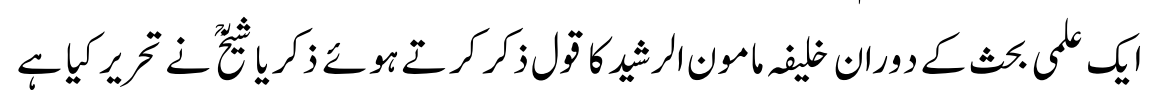

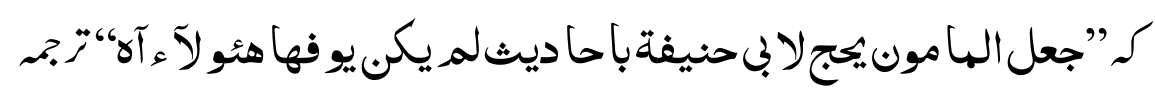

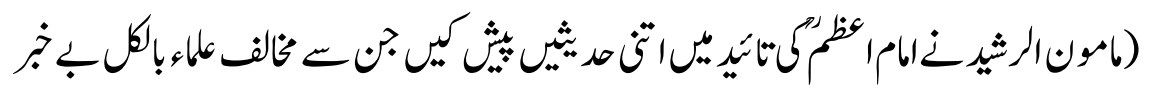

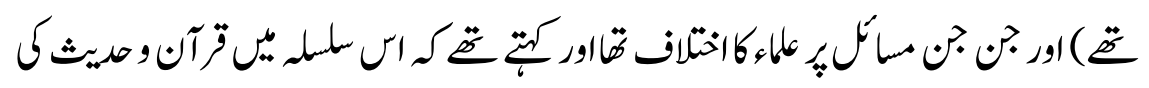

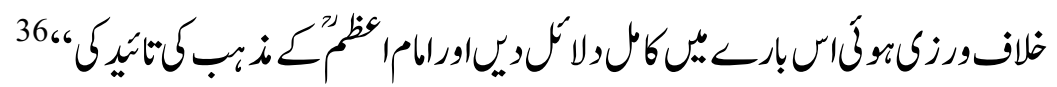




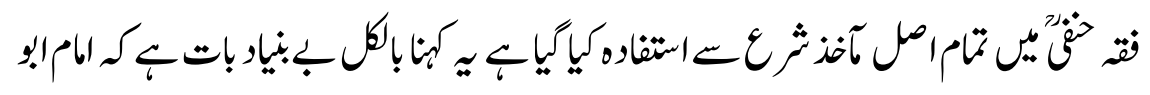

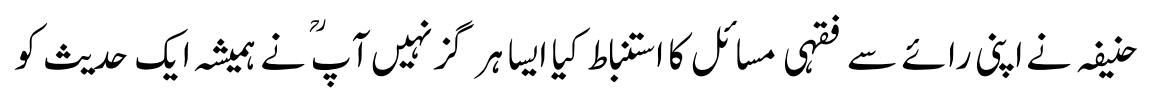

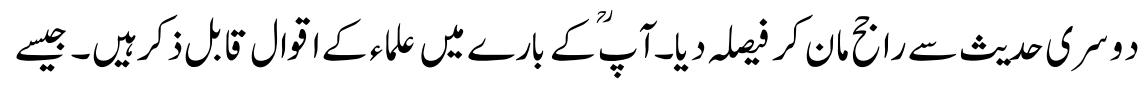

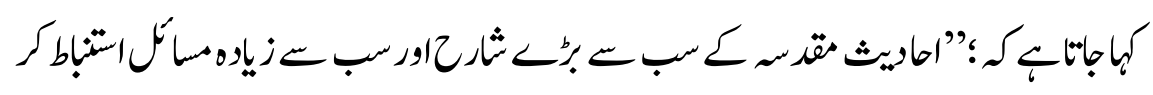

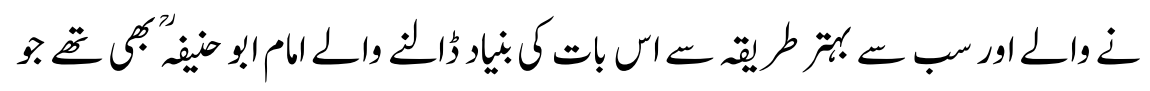

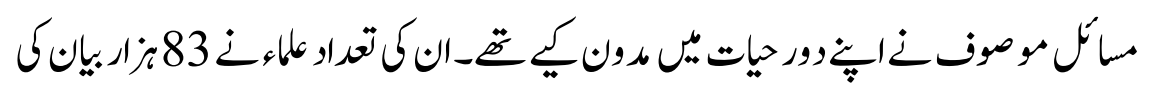

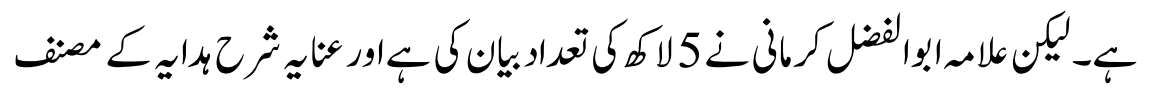

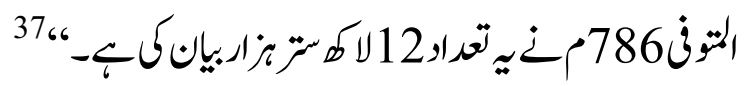

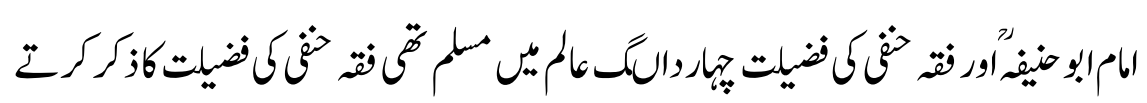

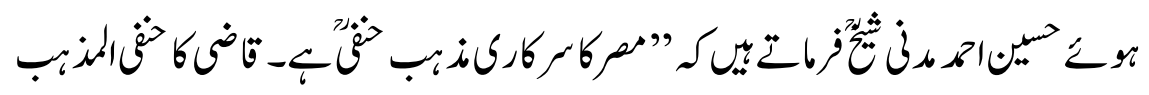
توناضروركبـ،

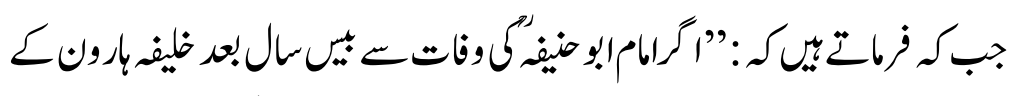

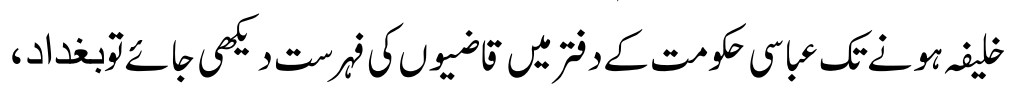

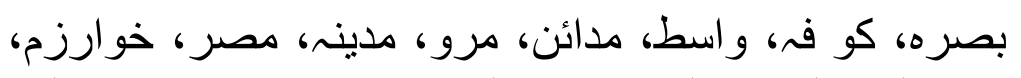

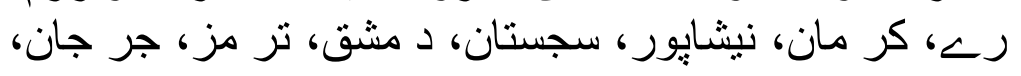

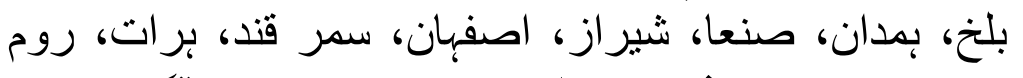

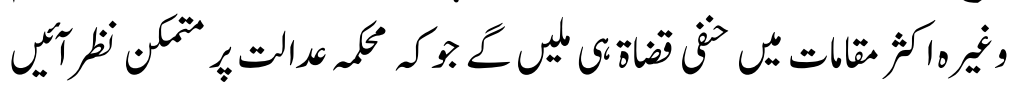
$396, \Sigma$

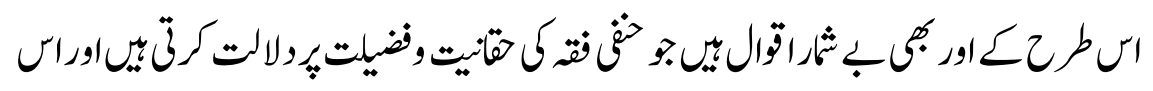

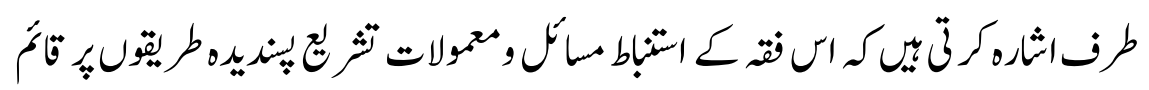

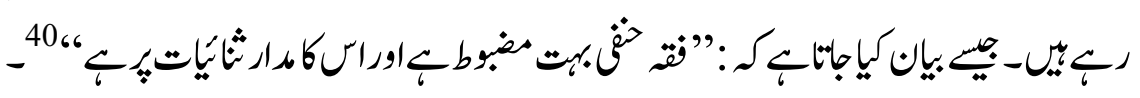




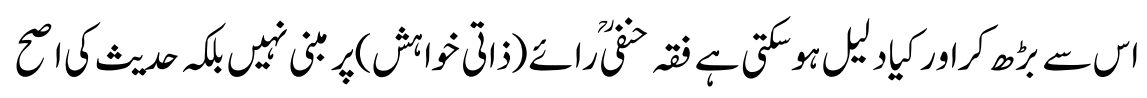

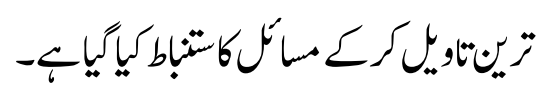

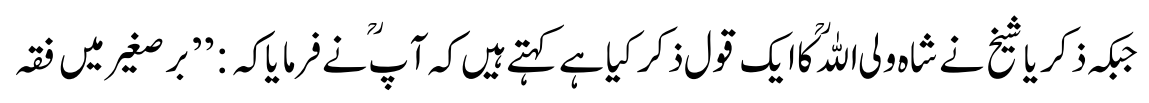

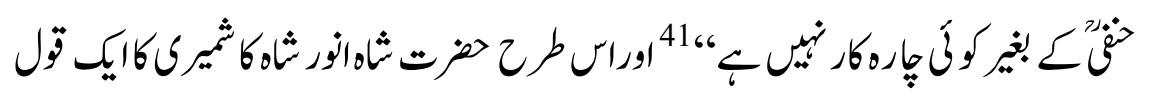

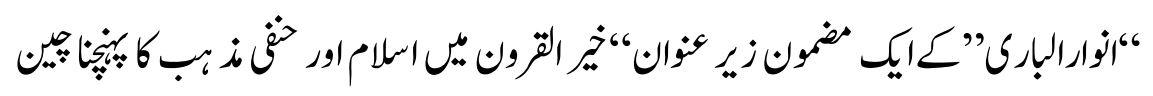

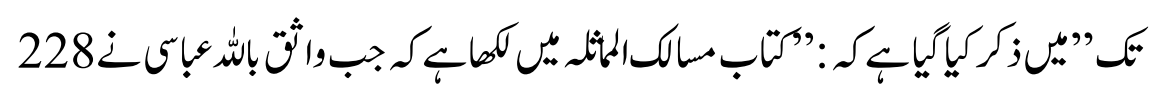

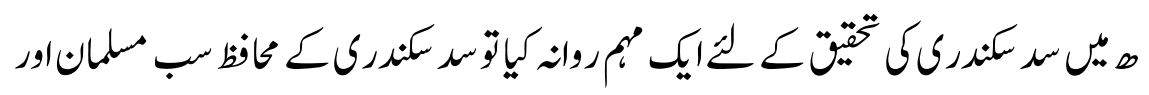

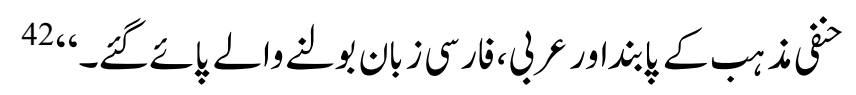

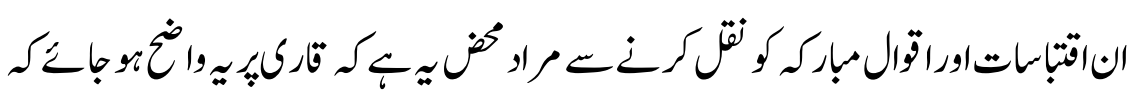

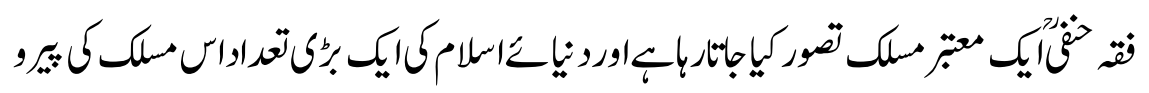

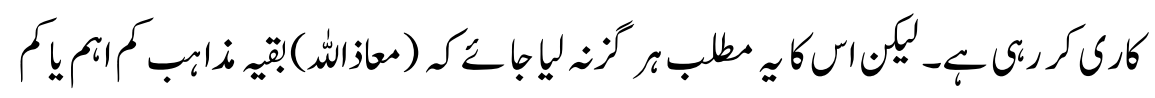

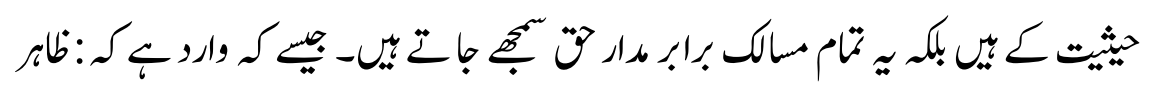

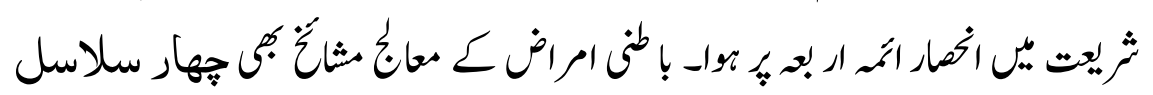

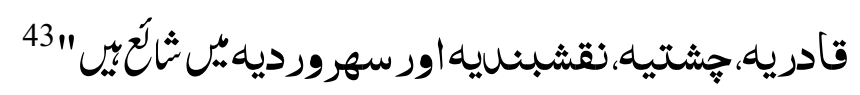

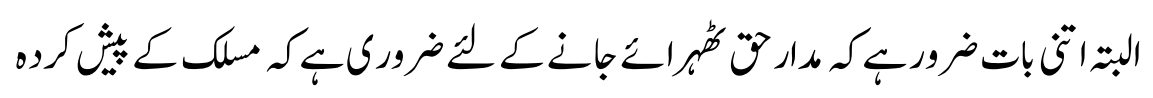

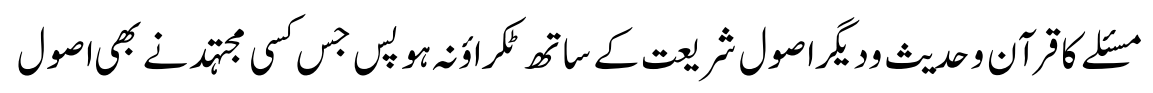

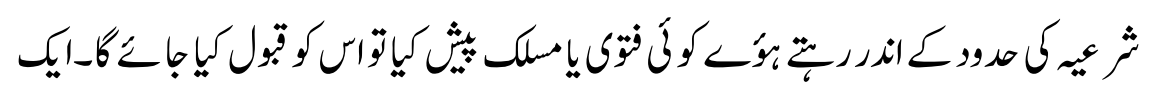

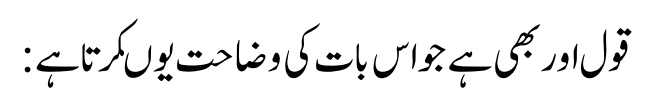

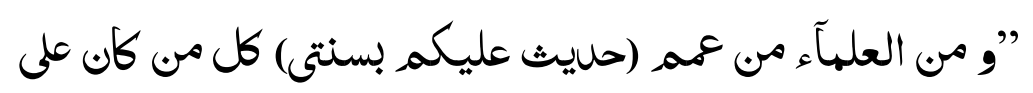

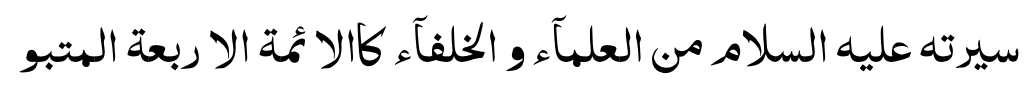

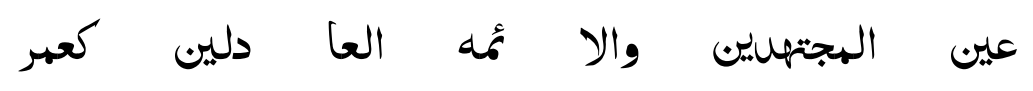




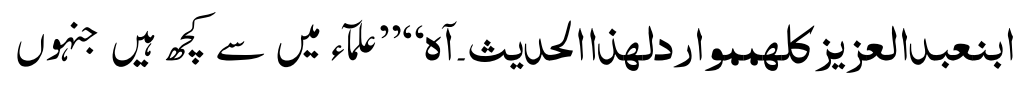

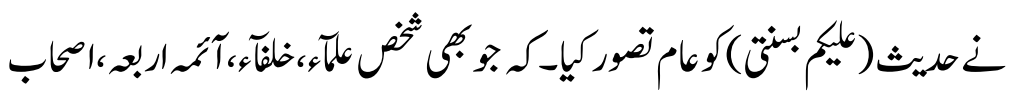

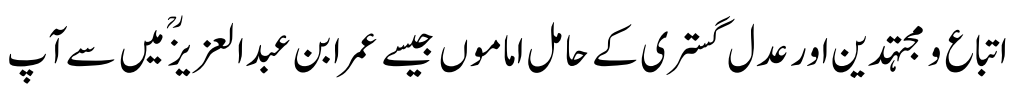

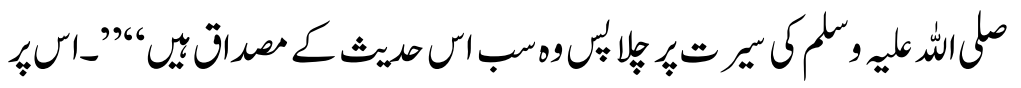

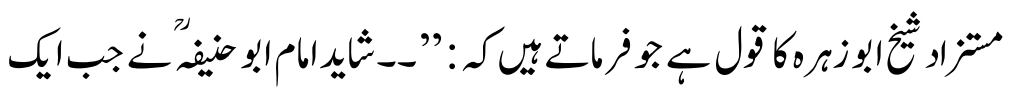

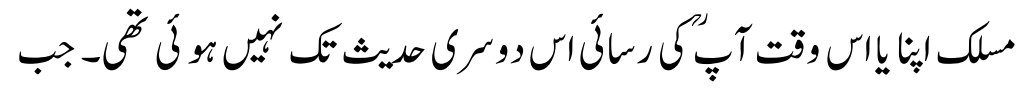

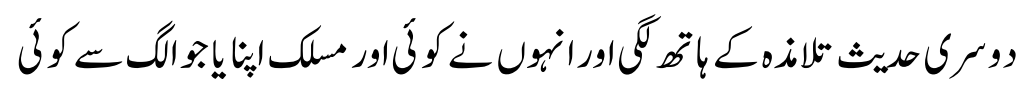

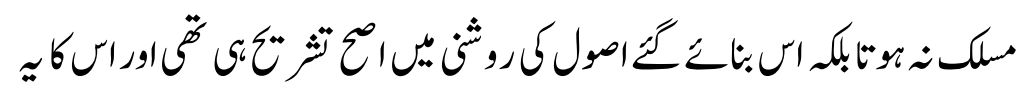

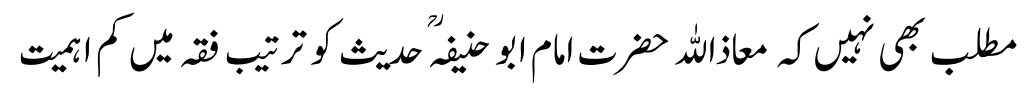

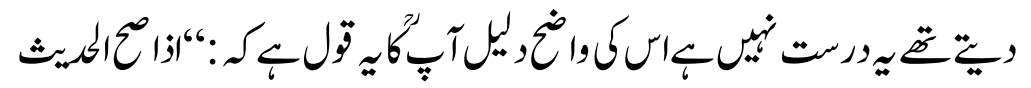

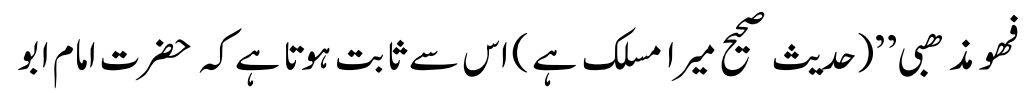

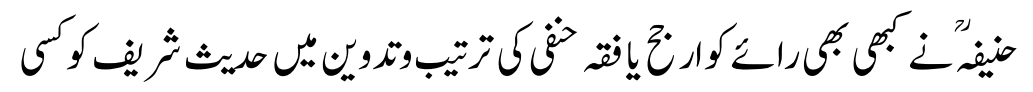

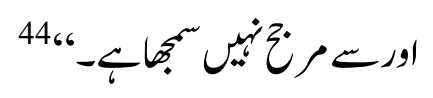

فلاص.كث:

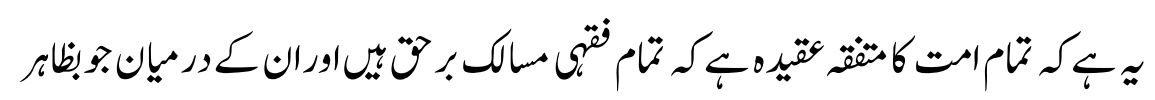

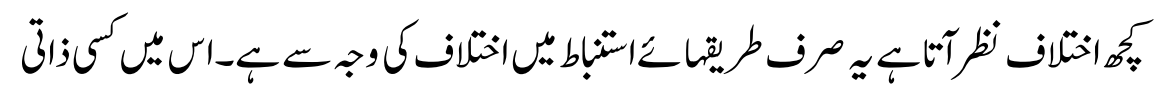

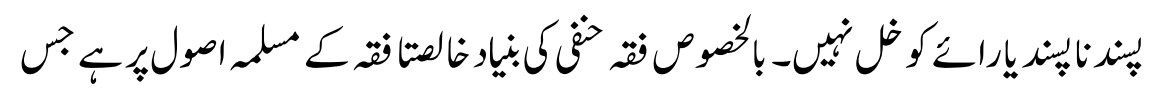

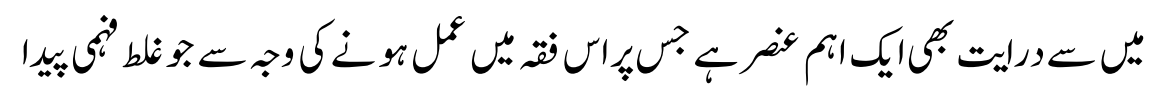

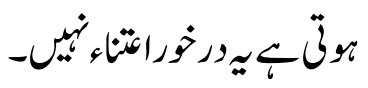

والرجات

1 
2

$$
\text { } 3
$$

$$
7
$$

8

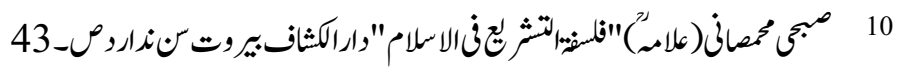

$$
11
$$

12

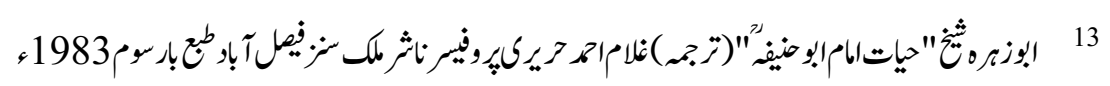

$$
\text { ص-101 }
$$

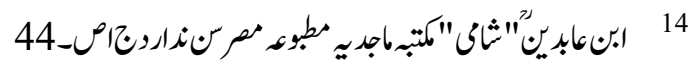

$$
16 \text { } 16
$$

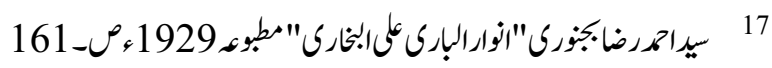

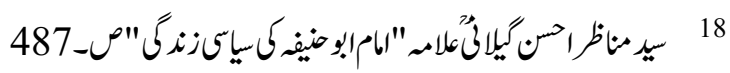

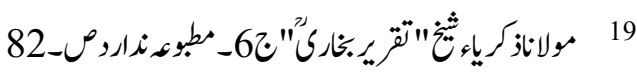

$$
\begin{aligned}
& 20
\end{aligned}
$$

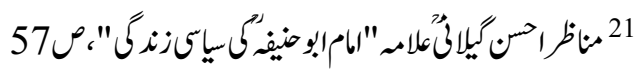




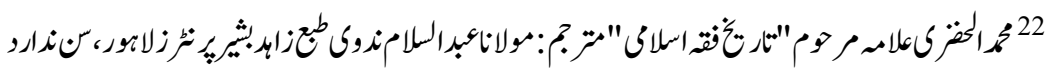
ص-324-321

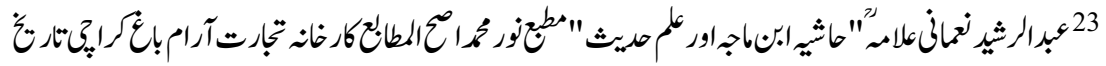
نزار,ص-166

$$
24
$$

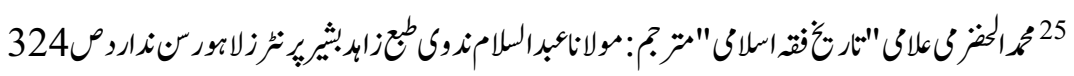

$$
\begin{aligned}
& 26 \text { ابن عبرابر"الانقاء"مطوء قايره1350ه، ص143 } \\
& 27
\end{aligned}
$$

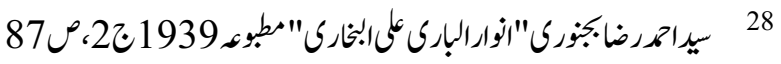

$$
29
$$

30 31

33

$$
\text { 35 } 34
$$

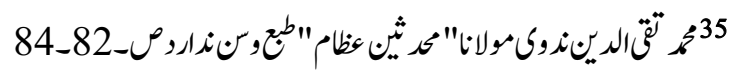

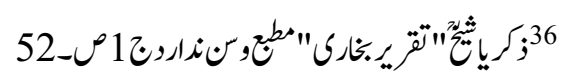

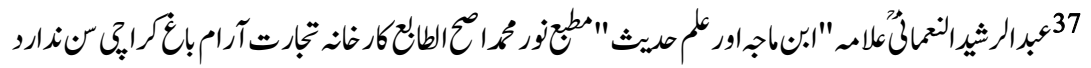

$$
\text { صـ14 }
$$

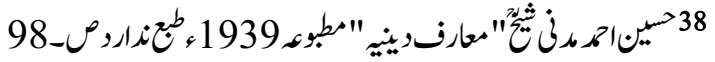

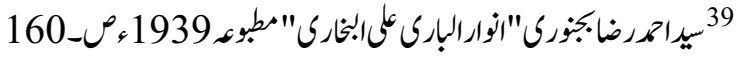




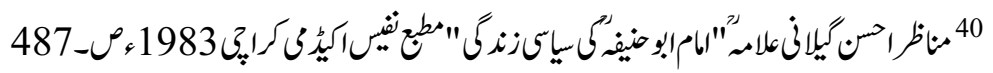

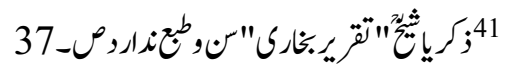

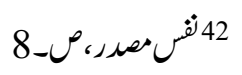

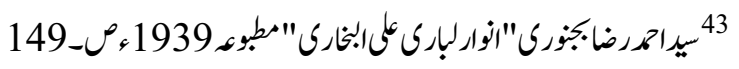

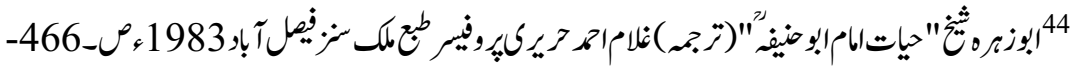

